\title{
The comprehensive model system COSMO-ART - Radiative impact of aerosol on the state of the atmosphere on the regional scale
}

\author{
B. Vogel, H. Vogel, D. Bäumer, M. Bangert, K. Lundgren, R. Rinke, and T. Stanelle \\ Institut für Meteorologie und Klimaforschung, Karlsruhe Institute of Technology (KIT), Karlsruhe Germany \\ Received: 16 March 2009 - Published in Atmos. Chem. Phys. Discuss.: 3 July 2009 \\ Revised: 9 October 2009 - Accepted: 23 October 2009 - Published: 16 November 2009
}

\begin{abstract}
A new fully online coupled model system developed for the evaluation of the interaction of aerosol particles with the atmosphere on the regional scale is described. The model system is based on the operational weather forecast model of the Deutscher Wetterdienst. Physical processes like transport, turbulent diffusion, and dry and wet deposition are treated together with photochemistry and aerosol dynamics using the modal approach. Based on detailed calculations we have developed parameterisations to examine the impact of aerosol particles on photolysis and on radiation. Currently the model allows feedback between natural and anthropogenic aerosol particles and the atmospheric variables that are initialized by the modification of the radiative fluxes. The model system is applied to two summer episodes, each lasting five days, with a model domain covering Western Europe and adjacent regions. The first episode is characterised by almost cloud free conditions and the second one by cloudy conditions. The simulated aerosol concentrations are compared to observations made at 700 stations distributed over Western Europe.

For each episode two model runs are performed; one where the feedback between the aerosol particles and the atmosphere is taken into account and a second one where the feedback is neglected. Comparing these two sets of model runs, the radiative feedback on temperature and other variables is evaluated.
\end{abstract}

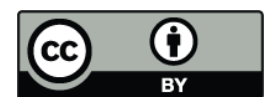

Correspondence to: B. Vogel

(bernhard.vogel@kit.edu)
In the cloud free case a clear correlation between the aerosol optical depth and changes in global radiation and temperature is found. In the case of cloudy conditions the pure radiative effects are superposed by changes in the liquid water content of the clouds due to changes in the thermodynamics of the atmosphere. In this case the correlation between the aerosol optical depth and its effects on temperature is low. However, on average a decrease in the $2 \mathrm{~m}$ temperature is still found.

For the area of Germany we found on average for both cases a reduction in the global radiation of about $6 \mathrm{~W} \mathrm{~m}^{2}$, a decrease of the $2 \mathrm{~m}$ temperature of $0.1 \mathrm{~K}$, and a reduction in the daily temperature range of $-0.13 \mathrm{~K}$.

\section{Introduction}

Aerosol particles modify atmospheric radiative fluxes and interact with clouds. As documented in the IPCC 2007 report the global influence of natural and anthropogenic aerosols on the atmosphere is not well understood. As shown by recently published and contradictive findings the state of knowledge is even worse concerning the effects of aerosol particles on radiation, temperature, and cloud formation on the regional scale (Bäumer and Vogel, 2007, 2008; Franssen, 2008; Bell et al., 2008). Beside observations, numerical models are important tools to improve our current understanding of the role of natural and anthropogenic aerosol particles for the state of the atmosphere. On the global scale there exist a large number of model systems and corresponding applications of models addressing the quantification of the effect of anthropogenic aerosol particles on climate change (e.g. Lohmann,

Published by Copernicus Publications on behalf of the European Geosciences Union. 
2008; Hoose et al., 2008; Bäumer et al., 2007). Due to a lack of computer capacity global climate models however often include simplifications and approximations (Lohmann and Schwartz, 2009). For example, Stier et al. (2005) prescribe the spatial distribution of important gaseous compounds that are involved in the formation and the dynamics of the aerosol particles.

On the cloud resolving scale several studies concerning the influence of aerosols and cloud formation can be found also (Khain et al., 2004; Levin et al., 2005; Cui et al., 2006). These model systems do not account for the radiative interaction of aerosol particles, cloud droplets and other hydrometeors. Most often the aerosols are treated in a very general manner within these models. One example is to categorize the aerosols as continental or maritime respectively, with prescribed size distributions that are kept constant during the simulation (Noppel et al., 2007).

On the continental to the regional scale there also exist several model systems which treat atmospheric processes, chemistry and aerosol dynamics. However, most of these model systems focus on air quality problems (Zhang, 2008 and references therein; Stern et al., 2008).

When studying feedback processes between aerosol particles and the atmosphere it is necessary to use online coupled model systems. Here, online coupled means that one identical numerical grid for the atmospheric variables and for the gaseous and particulate matter is used. In addition identical physical parameterisations are used for atmospheric processes such as turbulence and convection. In such a fully online coupled model system all variables are available at the same time step without spatial or temporal interpolation. It allows studying feedback processes between meteorology, emissions and chemical composition. Those online coupled models have to treat the relevant physical, chemi$\mathrm{cal}$, and aerosol dynamical processes at a comparable level of complexity. Meteorological pre- or postprocessors are not needed.

Currently only a limited number of model systems exist fulfilling these requirements (Zhang, 2008). Studying atmospheric processes with grid sizes down to a few kilometres requires a non-hydrostatic formulation of the model equations on the regional scale where phenomena such as mountain and valley winds, land-sea breezes or lee waves become important (Wippermann, 1980). This again reduces the number of available model systems. One example of such a fully online coupled model system is the WRF/Chem model (Grell et al., 2005).

We have developed a new online coupled model system which is based on the operational weather forecast model COSMO (Consortium for Small-scale Modelling; Steppeler et al., 2002) developed at the Deutscher Wetterdienst. Processes such as gas-phase chemistry, aerosol dynamics, and the impact of natural and anthropogenic aerosol particles on the state of the atmosphere are taken into account. As the radiative fluxes are modified based on the currently simulated aerosol distribution a quantification of several feedback processes is possible. In the first part of the paper we will give an outline of the current status of the model system. In the second part we address the effect of soot and secondary aerosols on radiation and temperature over Europe by applying the model system to two episodes in August 2005. In order to quantify the feedback mechanisms caused by the interaction of aerosol particles and radiation separately, the interactions of the aerosol particle with cloud microphysics are neglected.

\section{Model description}

Based on the mesoscale model system KAMM/DRAIS/ MADEsoot/dust (Riemer et al., 2003a; Vogel et al., 2006) we have developed an enhanced model system to simulate the spatial and temporal distribution of reactive gaseous and particulate matter. The meteorological module of the former model system was replaced by the operational weather forecast model COSMO of the Deutscher Wetterdienst (DWD). The name of the new model system is COSMO-ART (ART stands for Aerosols and Reactive Trace gases). Gas phase chemistry and aerosol dynamics are online coupled with the operational version of the COSMO model. That means that in addition to transport of a non reactive tracer, the dispersion of chemical reactive species and aerosols can be calculated. Secondary aerosols formed from the gas phase and directly emitted components like soot, mineral dust, sea salt and biological material are all represented by log normal distributions. Processes as coagulation, condensation and sedimentation are taken into account. The emissions of biogenic VOCs (volatile organic compounds), dust particles, sea salt and pollen are also calculated online at each time step as functions of meteorological variables. To calculate the photolysis frequencies a new efficient method was developed using the GRAALS (General Radiative Algorithm Adapted to Linear-type Solutions) radiation scheme (Ritter and Geleyn, 1992), which is already implemented in the COSMO model. With this regional scale model system we want to quantify feedback processes between aerosols and the state of the atmosphere together with the interaction between trace gases and aerosols. The model system can be embedded by one way nesting into individual global scale models as the GME model (Global model of the DWD) or the IFS (Integrated Forecast System) model of ECMWF (European Centre for Medium-Range Weather Forecasts). Figure 1 gives an overview of the new model system.

When developing COSMO-ART we applied the concept of using identical methods to calculate the transport of all scalars, i.e. temperature, humidity, and concentrations of gases and aerosols. This also includes the treatment of deep convection with the Tiedtke scheme (Tiedtke, 1989). As COSMO-ART has a modular structure specific processes as chemistry or aerosol dynamics can be easily substituted by alternative parameterisations. 


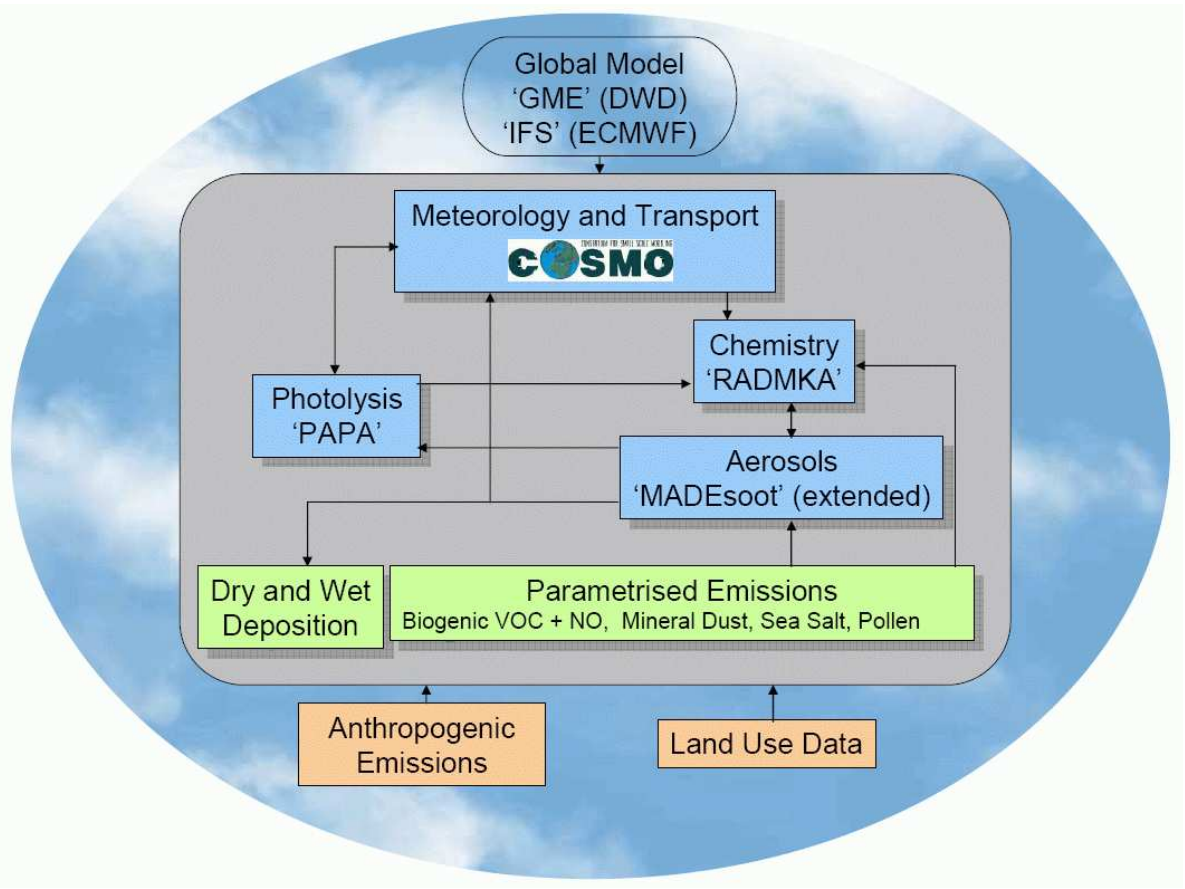

Fig. 1. The model system COSMO-ART.

\subsection{The extended version of MADEsoot}

In MADEsoot (Modal Aerosol Dynamics Model for Europe extended by Soot), several overlapping modes represent the aerosol population, which are approximated by lognormal functions. Currently, we use five modes for the sub-micron particles. Two modes (if and $j f$ ) represent secondary particles consisting of sulphate, ammonium, nitrate, organic compounds (SOA), and water, one mode $(s)$ represents pure soot and two more modes (ic and $j c$ ) represent aged soot particles consisting of sulphate, ammonium, nitrate, organic compounds, water, and soot. The modes if and ic represent the Aitken mode particles and $j f$ and $j c$ the accumulation mode particles, respectively. The modes if, jf, ic and $j c$ are assumed to be internally mixed. All modes are subject to condensation and coagulation. The growth rate of the particles due to condensation is calculated following Binkowski and Shankar (1995) depending on the available mass of the condensable species and the size distribution of the particles. In case of coagulation, the assignment to the individual modes follows the method of Whitby et al. (1991): (1) Particles formed by intramodal coagulation stay in their original modes. (2) Particles formed by intermodal coagulation are assigned to the mode with the larger median diameter. Furthermore, a thermodynamic equilibrium of gas phase and aerosol phase is applied to calculate the concentrations of sulphate, ammonium, nitrate and water (Kim et al., 1993).

The source of the secondary inorganic particles in modes if and $j f$ is the binary nucleation of sulphuric acid and water.
The nucleation rates are calculated using the parameterisation of Kerminen and Wexler (1994). The secondary organic compounds are treated according to Schell et al. (2001).The two product approach of Odum et al. (1996) is used and eight parent organic compounds are treated which are oxidised to form condensable species.

The soot particles in mode $s$ are directly emitted into the atmosphere. Direct emissions of sulphate and primary organics into modes if, ic, jf, and $j c$ are not taken into account. The particles in mode $i c$ and $j c$ are formed due to the aging process. Two processes can impact the transfer of soot from external into internal mixture, namely coagulation and condensation. Coagulation of soot particles in mode $s$ with particles in modes if, jf, ic or jc transfers the mass of mode $s$ into the modes $i c$ or $j c$. As a second process, condensation of sulphuric acid on the surface of the soot particles and the subsequent formation of ammonium sulphate and the condensation of organic material can transfer soot into an internal mixture as well. Following Weingartner et al. (1997) we define that all material of mode $s$ is moved to modes $i c$ and $j c$ if the soluble mass fraction of mode $s$ rises above the threshold value $\varepsilon=5 \%$. Thus, the ageing of the soot particles is treated explicitly (Riemer et al., 2004) which is of great importance with respect to their radiative effects (Jacobson, 2000; Riemer et al., 2003a). Additionally, sedimentation, advection and turbulent diffusion can modify the aerosol distributions. The coarse mode $c$ contains additional anthropogenic emitted particles. Table 1 gives an overview of the standard deviation and the chemical composition of 
Table 1. Mixing state, chemical composition, and standard deviation of the individual modes of the aerosol particles.

\begin{tabular}{llc}
\hline Mode & Chemical composition and mixing state & Standard deviation \\
\hline if & $\mathrm{SO}_{4}^{2-}, \mathrm{NO}_{3}^{-}, \mathrm{NH}_{4}^{+}, \mathrm{H}_{2} \mathrm{O}, \mathrm{SOA}$ (internally mixed) & 1.7 \\
ic & $\mathrm{SO}_{4}^{2-}, \mathrm{NO}_{3}^{-}, \mathrm{NH}_{4}^{+}, \mathrm{H}_{2} \mathrm{O}, \mathrm{SOA}$, soot (internally mixed) & 1.7 \\
jf & $\mathrm{SO}_{4}^{2-}, \mathrm{NO}_{3}^{-}, \mathrm{NH}_{4}^{+}, \mathrm{H}_{2} \mathrm{O}, \mathrm{SOA}$ (internally mixed) & 2.0 \\
$j c$ & $\mathrm{SO}_{4}^{2-}, \mathrm{NO}_{3}^{-}, \mathrm{NH}_{4}^{+}, \mathrm{H}_{2} \mathrm{O}, \mathrm{SOA}$, soot (internally mixed) & 2.0 \\
$s$ & soot & 1.4 \\
$c$ & direct $\mathrm{PM}_{10}$ emissions & 2.5 \\
\hline
\end{tabular}

each mode. Furthermore, COSMO-ART also treats mineral dust (Stanelle, 2008), sea salt (Lundgren, 2006), and pollen (Vogel et al., 2008).

For each mode prognostics equations for the number density and the mass concentration are solved. The standard deviations are kept constant. The zeroth moment $M_{0, l}$ gives the total number density of mode 1 . To be consistent with the treatment of temperature and humidity within COSMO-ART the number density and the mass concentration are normalized with the total number density of air molecules $\mathrm{N}$ and with the total mass concentration of humid air $\rho$, respectively:

$\Psi_{0, l}=\frac{M_{0, l}}{\mathrm{~N}}$

and

$\Psi_{n, l}=\frac{\mathrm{m}_{n, l}}{\rho}$

$\mathrm{m}_{n, l}$ denotes the mass concentration of the chemical compound $n$ of the aerosol.

In COSMO-ART the following equations are solved numerically for the normalized number density of each mode.

- For modes if and ic:

$$
\begin{aligned}
& \frac{\partial \hat{\Psi}_{0, i f}}{\partial t}=-\hat{\mathbf{v}} \cdot \nabla \hat{\Psi}_{0, \text { if }}-\bar{v}_{\text {sed }, 0, i f} \frac{\partial \hat{\Psi}_{0, i f}}{\partial z}+\frac{1}{\bar{\rho}} \nabla \cdot F \\
& -\bar{W}_{0, i f}-\overline{\mathrm{Ca}}_{0, \text { if } \text { if }}-\overline{\mathrm{Ca}}_{0, \text { if } j f}-\overline{\mathrm{Ca}}_{0, \text { if } i c}-\overline{\mathrm{Ca}}_{0, \text { if } j c} \\
& -\overline{\mathrm{Ca}}_{0, \text { if } s}+\overline{\mathrm{Nu}}_{0},
\end{aligned}
$$

$\frac{\partial \hat{\Psi}_{0, i c}}{\partial t}=-\hat{\mathbf{v}} \cdot \nabla \hat{\Psi}_{0, i c}-\bar{v}_{\mathrm{sed}, 0, i c} \frac{\partial \hat{\Psi}_{0, i c}}{\partial z}+\frac{1}{\bar{\rho}} \nabla \cdot F^{\Psi_{0, i c}}$

$-\bar{W}_{0, i c}-\overline{\mathrm{Ca}}_{0, i c i c}-\overline{\mathrm{Ca}}_{0, i c j c}$

$-\overline{\mathrm{Ca}}_{i c j f}+\overline{\mathrm{Ca}}_{0, \text { if } s}$,

- for the modes jf and $j c$ :

$$
\begin{aligned}
& \frac{\partial \hat{\Psi}_{0, j f}}{\partial t}=-\hat{\mathbf{v}} \cdot \nabla \hat{\Psi}_{0, j f}-\bar{v}_{\text {sed }, 0, j f} \frac{\partial \hat{\Psi}_{0, j f}}{\partial z}+\frac{1}{\bar{\rho}} \nabla \cdot F^{\Psi_{0, j f}} \\
& -\bar{W}_{0, j f}-\overline{\mathrm{Ca}}_{0, j f \text { jf }}-\overline{\mathrm{Ca}}_{0, j f i c} \\
& -\overline{\mathrm{Ca}}_{0, j f j c}-\overline{\mathrm{Ca}}_{0, j f s},
\end{aligned}
$$

$\frac{\partial \hat{\Psi}_{0, j c}}{\partial t}=-\hat{\mathbf{v}} \cdot \nabla \hat{\Psi}_{0, j c}-\bar{v}_{\text {sed }, 0, j c} \frac{\partial \hat{\Psi}_{0, j c}}{\partial z}+\frac{1}{\bar{\rho}} \nabla \cdot F^{\Psi_{0, j c}}$

$-\bar{W}_{0, j c}-\overline{\mathrm{Ca}}_{0, j c j c}+$

$\overline{\mathrm{Ca}}_{0, j c i c}+\overline{\mathrm{Ca}}_{0, j f s}$,

- for the soot mode $s$ :

$\frac{\partial \hat{\Psi}_{0, s}}{\partial t}=-\hat{\mathbf{v}} \cdot \nabla \hat{\Psi}_{0, s}-\bar{v}_{\text {sed }, 0, s} \frac{\partial \hat{\Psi}_{0, s}}{\partial z}+\frac{1}{\bar{\rho}} \nabla \cdot F^{\Psi_{0, s}}$

$-\bar{W}_{0, s}-\overline{\mathrm{Ca}}_{0, s s}-\overline{\mathrm{Ca}}_{0, \text { if } s}-\overline{\mathrm{Ca}}_{0, j f s}$

$-\overline{\mathrm{Ca}}_{0, i c s}-\overline{\mathrm{Ca}}_{0, j c s}$,

- and for the coarse mode $c$ :

$\frac{\partial \hat{\Psi}_{0, c}}{\partial t}=-\hat{\mathbf{v}} \cdot \nabla \hat{\Psi}_{0, c}-\bar{v}_{\mathrm{sed}, 0, c} \frac{\partial \hat{\Psi}_{0, c}}{\partial z}+\frac{1}{\bar{\rho}} \nabla \cdot F^{\Psi_{0, c}}-\bar{W}_{0, c}$.

$\hat{\mathbf{v}}$ is the wind vector, $\bar{v}_{\text {sed }, 0, l}$ the sedimentation velocity for the zeroth moment and $F^{\Psi_{0, l}}$ the turbulent flux for the zeroth moment of the mode $1 . \bar{W}_{0, l}$ describes the loss of particles due to precipitation scavenging and is parameterised according to Rinke (2008). The term $\overline{\mathrm{Ca}}_{0, l_{1} l_{2}}$ describes the changes of the zeroth moment due to coagulation, and $\overline{\mathrm{Nu}}_{0, l}$ describes the increase of the zeroth moment due to nucleation. The hat denotes the density weighted Reynolds average that is given by:

$\hat{\Psi}=\frac{\overline{\rho \Psi}}{\bar{\rho}}$.

The number densities of the coarse mode are small. Therefore the Inter-modal coagulation between the coarse mode and the other modes and the intra-modal coagulation of the coarse mode particles are both neglected. From the numbers we calculated for the individual modes we found that the 
intermodal coagulation between the nucleation mode (that gives the highest number densities) and the coarse mode is two orders of magnitude less than the inter-modal coagulation of the nucleation mode particles and the accumulation mode particles.

In addition to the balance equations for the normalized number density given above, the balance equations for the normalized mass concentration are solved. Since a thermodynamical equilibrium is assumed for the system of sulphate, nitrate, ammonium and water, balance equations are only solved for sulphate, soot, SOA and the coarse mode. This leads to the Reynolds-averaged balance equations for the respective modes as follows:

- For the modes if and ic:

$$
\begin{aligned}
& \frac{\partial \hat{\Psi}_{\text {sulf }, i f}}{\partial t}=-\hat{\mathbf{v}} \cdot \nabla \hat{\Psi}_{\text {sulf }, i f}-\bar{v}_{\text {sed, sulf }, \text { if }} \frac{\partial \hat{\Psi}_{\text {sulf }, i f}}{\partial z}+\frac{1}{\bar{\rho}} \nabla \cdot F^{\Psi_{\text {sulf }, i f}} \\
& -\bar{W}_{\text {sulf }, \text { if }}-\left(\overline{\mathrm{Ca}}_{3, \text { if } j f}+\overline{\mathrm{Ca}}_{3, \text { if ic }}+\overline{\mathrm{Ca}}_{3, \text { if } j c}+\overline{\mathrm{Ca}}_{3, \text { if } s}\right) \\
& \frac{\hat{\Psi}_{\text {sulf }, i f}}{M_{3, i f}}+\overline{\mathrm{Co}}_{\text {sulf }, i f}+\overline{\mathrm{Nu}}_{\text {sulf }} \text {, } \\
& \frac{\partial \hat{\Psi}_{\text {sulf }, i c}}{\partial t}=-\hat{\mathbf{v}} \cdot \nabla \hat{\Psi}_{\text {sulf }, i c}-\bar{v}_{\text {sed, sulf }, i c} \frac{\partial \hat{\Psi}_{\text {sulf }, i c}}{\partial z}+\frac{1}{\bar{\rho}} \nabla \cdot F^{\Psi_{\text {sulf }, i c}} \\
& -\bar{W}_{\text {sulf }, i c}-\left(\overline{\mathrm{Ca}}_{3, i c j c}+\overline{\mathrm{Ca}}_{3, i c j f}\right) \frac{\hat{\Psi}_{\text {sulf }, i c}}{M_{3, i c}} \\
& +\left(\overline{\mathrm{Ca}}_{3, \text { if } i c}+\overline{\mathrm{Ca}}_{3, \text { if } s}\right) \frac{\hat{\Psi}_{\text {sulf }, i f}}{M_{3, i f}}+\overline{\mathrm{Co}}_{\text {sulf }, i c},
\end{aligned}
$$

- for the modes $j f$ and $j c$ :

$$
\begin{aligned}
& \frac{\partial \hat{\Psi}_{\text {sulf }, j f}}{\partial t}=-\hat{\mathbf{v}} \cdot \nabla \hat{\Psi}_{\text {sulf }, j f}-\bar{v}_{\text {sed, sulf }, j f} \frac{\partial \hat{\Psi}_{\text {sulf }, j f}}{\partial z}+\frac{1}{\bar{\rho}} \nabla \cdot F^{\Psi_{\text {sulf }, j f}} \\
& -\bar{W}_{\text {sulf }, j f}-\left(\overline{\mathrm{Ca}}_{3, j f} j c+\overline{\mathrm{Ca}}_{3, j f i c}+\overline{\mathrm{Ca}}_{3, j f s}\right) \\
& \frac{\hat{\Psi}_{\text {sulf }, j f}}{M_{3, j f}}+\overline{\mathrm{Ca}}_{3, \text { if } j f} \frac{\hat{\Psi}_{\text {sulf }, i f}}{M_{3, i f}}+\overline{\mathrm{Co}}_{\text {sulf }, j f}
\end{aligned}
$$

$\frac{\partial \hat{\Psi}_{\text {sulf }, j c}}{\partial t}=-\hat{\mathbf{v}} \cdot \nabla \hat{\Psi}_{\text {sulf }, j c}-\bar{v}_{\text {sed }, \text { sulf }, j c} \frac{\partial \hat{\Psi}_{\text {sulf }, j c}}{\partial z}+\frac{1}{\bar{\rho}} \nabla \cdot F^{\Psi_{\text {sulf }, j c}}$

$-\bar{W}_{\text {sulf }, j c}+\overline{\mathrm{Ca}}_{3, i f} j c \frac{\hat{\Psi}_{\text {sulf }, i f}}{M_{3, j f}}+\left(\overline{\mathrm{Ca}}_{3, i c j c}+\overline{\mathrm{Ca}}_{3, i c j f}\right)$

$\frac{\hat{\Psi}_{\text {sulf }, \mathrm{ic}}}{M_{3, i c}}+\left(\overline{\mathrm{Ca}}_{3, j f j c}+\overline{\mathrm{Ca}}_{3, j f s}+\overline{\mathrm{Ca}}_{3, j f i c}\right)$

$\frac{\hat{\Psi}_{\text {sulf }, j f}}{M_{3, j f}}+\overline{\mathrm{Co}}_{\text {sulf }, j c}$,
- for the soot content of the soot containing modes $i c$ and jc:

$$
\begin{aligned}
& \frac{\partial \hat{\Psi}_{s, i c}}{\partial t}=-\hat{\mathbf{v}} \cdot \nabla \hat{\Psi}_{s, i c}-\bar{v}_{\text {sed }, s, i c} \frac{\partial \hat{\Psi}_{s, i c}}{\partial z}+\frac{1}{\bar{\rho}} \nabla \cdot F^{\Psi_{s, i c}} \\
& -\bar{W}_{s, i c}+\left(\overline{\mathrm{Ca}}_{3, s i f}+\overline{\mathrm{Ca}}_{3, s i c}\right) \frac{\hat{\Psi}_{s, s}}{M_{3, s}} \\
& -\left(\overline{\mathrm{Ca}}_{3, i c j c}+\overline{\mathrm{Ca}}_{3, i c j f}\right) \frac{\hat{\Psi}_{s, i c}}{M_{3, i c}}
\end{aligned}
$$

$\frac{\partial \hat{\Psi}_{s, j c}}{\partial t}=-\hat{\mathbf{v}} \cdot \nabla \hat{\Psi}_{s, j c}-\bar{v}_{\text {sed }, s, i c} \frac{\partial \hat{\Psi}_{s, j c}}{\partial z}+\frac{1}{\bar{\rho}} \nabla \cdot F^{\Psi_{s, j c}}$

$-\bar{W}_{s, j c}+\left(\overline{\mathrm{Ca}}_{3, s j f}+\overline{\mathrm{Ca}}_{3, s j c}\right) \frac{\hat{\Psi}_{s, s}}{M_{3, s}}$

$+\left(\overline{\mathrm{Ca}}_{3, i c j c}+\overline{\mathrm{Ca}}_{3, i c j f}\right) \frac{\hat{\Psi}_{s, i c}}{M_{3, i c}}$

- for the pure soot mode $s$ :

$$
\begin{aligned}
& \frac{\partial \hat{\Psi}_{s, s}}{\partial t}=-\hat{\mathbf{v}} \cdot \nabla \hat{\Psi}_{s, s}-\bar{v}_{\text {sed }, s, s} \frac{\partial \hat{\Psi}_{s, s}}{\partial z}+\frac{1}{\bar{\rho}} \nabla \cdot F^{\Psi_{s, s}}-\bar{W}_{s, s} \\
& -\left(\overline{\mathrm{Ca}}_{3, s i f}+\overline{\mathrm{Ca}}_{3, s j f}+\overline{\mathrm{Ca}}_{3, s i c}+\overline{\mathrm{Ca}}_{3, s}\right) \frac{\hat{\Psi}_{s, s}}{M_{3, s}},
\end{aligned}
$$

- the coarse mode $c$ :

$$
\frac{\partial \hat{\Psi}_{c, c}}{\partial t}=-\hat{\mathbf{v}} \cdot \nabla \hat{\Psi}_{c, c}-\bar{v}_{\text {sed }, c, c} \frac{\partial \hat{\Psi}_{c, c}}{\partial z}+\frac{1}{\bar{\rho}} \nabla \cdot F^{\Psi_{c, c}}-\bar{W}_{c, c} .
$$

$\bar{v}_{\text {sed }, n, l}$ is the sedimentation velocity with respect to mass in mode 1 and $F^{\Psi_{3, l}}$ is the turbulent flux for the normalized mass concentration of mode 1 . In addition, no intramodal coagulation terms appear in the equations for the normalized mass densities, as they do not change this quantity.

$M_{3, l}$ is the third moment of mode 1 . Similar equations as Eqs. (10) to (13) are solved for the organic compounds of the aerosol particles and similar equations as Eqs. (8) and (17) are solved for mineral dust and sea salt.

The turbulent fluxes $F^{\Psi_{n, l}}$,

$$
F^{\Psi_{n, l}}=\overline{\rho v^{\prime \prime} \Psi_{n, l}^{\prime \prime}},
$$

in Eqs. (3)-(17) are parameterised in analogy to the turbulent fluxes in the diffusion equation and in the balance equation for water vapour in the COSMO model.

$\bar{W}_{n, l}$ describes the loss of particles due to precipitation scavenging and is parameterised according to Rinke (2008). The term $\overline{\mathrm{Ca}}_{3, l_{1} l_{2}}$ describes the transfer rate of the third moment of mode $l_{1}$ due to coagulation. $\overline{\mathrm{Co}}_{\text {sulf }, l}$ is the condensational loss or gain of mass and $\overline{\mathrm{Nu}}_{\text {sulf }}$ is the increase of mass due to nucleation.

A detailed description of the treatment of the sedimentation and dry deposition, coagulation, condensation, nucleation and the thermodynamical equilibrium of the aerosol species is given by Riemer (2002). 
Table 2. List of the used spectral range with the considered components of the atmosphere in the radiation model.

\begin{tabular}{|c|c|c|c|c|c|c|c|c|}
\hline & \multicolumn{8}{|c|}{ interval } \\
\hline & 1 & 2 & 3 & 4 & 5 & 6 & 7 & 8 \\
\hline $\begin{array}{l}\text { spectral range } \\
{[\mu \mathrm{m}]}\end{array}$ & $1.53-4.64$ & $0.7-1.53$ & $0.25-0.7$ & $20.0-104.5$ & $12.5-20.0$ & $\begin{array}{r}8.33-9.01 \\
10.31-12.5\end{array}$ & $9.01-10.31$ & $4.64-8.33$ \\
\hline
\end{tabular}

Source: Ritter and Geleyn (1992)

\subsection{Chemistry of RADMKA}

The chemical reactions of the gaseous species are calculated using the chemical mechanism RADMKA (Regional Acid Deposition Model Version Karlsruhe). This mechanism is based on RADM2 (Regional Acid Deposition Model; Stockwell et al., 1990) and includes several series of improvements. We have updated the reaction rates for $\mathrm{NO}_{2}+\mathrm{OH} \rightarrow \mathrm{HNO}_{3}$ (Donahue et al., 1997) and $\mathrm{HO}_{2}+\mathrm{NO} \rightarrow \mathrm{OH}+\mathrm{NO}_{2}$ (Bohn and Zetsch, 1997). The very simple treatment of the heterogeneous hydrolysis of $\mathrm{N}_{2} \mathrm{O}_{5}$ was also replaced by a more complete one that takes into account the actual aerosol concentration and its chemical composition (Riemer et al., 2003b). Furthermore, the rate constants for $\mathrm{NO}+\mathrm{OH} \rightarrow \mathrm{HONO}$ have been updated and a heterogeneous reaction that leads to the formation of HONO at surfaces has been included (Vogel et al., 2003). As was shown in Vogel et al. (2003) and Sarwar et al. (2008) HONO is an important source for $\mathrm{OH}$ under certain conditions. The very simple isoprene scheme of RADM 2 has been replaced by the more sophisticated one of Geiger et al. (2003). Additional biogenic and anthropogenic hydrocarbons that may serve as precursors for secondary organic components of the aerosol were added to RADMKA according to the SORGAM (Secondary Organic Aerosol Model) module by Schell et al. (2001). Currently, RADMKA does not take into account wet phase chemistry. This means that formation of sulphate in cloud droplets is not taken into account. Therefore, sulphate burden might be underestimated particularly in the "HC" case.

\subsection{Treatment of radiative fluxes}

Several processes in the atmosphere are affected by shortwave and longwave radiation. The divergence of the radiative fluxes contributes to the diabatic heating. The incoming and outgoing shortwave and longwave fluxes at the earth surface are major components of the energy balance and therefore drive the temporal variation of the surface temperature.

The vertical profiles of the radiative fluxes depend on those of temperature, pressure, the concentrations of water, $\mathrm{CO}_{2}, \mathrm{O}_{3}$, and the size distributions of the aerosol particles. The GRAALS radiation scheme (Ritter and Geleyn, 1992) is used within the COSMO model to calculate vertical profiles of the short- and longwave radiative fluxes. To perform fully coupled simulations with COSMO-ART the aerosol optical properties for each of the eight spectral bands of the GRAALS radiation scheme (Table 2) are required at every grid point and at every time step when the radiative fluxes are calculated. Those optical properties are the extinction coefficient, the single scattering albedo and the asymmetry factor. They depend on the size distributions of the aerosol particles, their chemical composition, as well as the soot and water content of the particles. The necessary Mie calculations can be performed with the detailed code of Bohren and Huffman (1983). However, the enormous amount of computer time inhibits the calculation of the optical properties at each grid point and at each time step. For this reason we have developed a parameterisation scheme for the optical properties based on a priori calculations using the scheme of Bohren and Huffmann and pre-calculated aerosol distributions. The a priori calculations are based on simulated aerosol particle size distributions and their chemical composition. These distributions were calculated with COSMO-ART where the feedback between the aerosol and the radiation was switched off. Detailed Mie calculations were then carried out for each grid-box of the model system. The results were plotted as functions of the wet aerosol mass or in case of the single scattering albedo and the asymmetry parameter as functions of the mass fraction. Applying fit procedures we derived the parameters given in Table 3. Hence, by this procedure our parameterisation is based on typical size distributions and chemical compositions that are simulated in our model domain. Since these calculations deliver the optical properties at single wavelengths numerous calculations are performed to determine the optical properties for the spectral wavelength bands required by GRAALS. The method we used for the weighting of the individual wavelength is described in Bäumer et al. (2007).

Finally, we ended up with the following parameterisation for the optical properties. The extinction coefficient $b_{k}$ for a specific wavelength interval is calculated by:

$b_{k}=\sum_{l} 10^{-6} \cdot \tilde{b}_{k, l} \cdot m_{l}$

$k$ denotes the wavelength interval, and $l$ denotes the modes if, $j f, i c, j c$, and $s$. The coefficients $\tilde{b}_{k, l}$ that were derived from a priori calculations are given in Table $3 . m_{l}$ is the total wet aerosol mass of mode 1 in $\mu \mathrm{g} \mathrm{m}^{-3}$. 
Table 3. Parameters derived from detailed Mie-calculations.

\begin{tabular}{cccccccccc}
\hline & & & & \multicolumn{6}{c}{$\mathrm{k}$} \\
& 1 & 1 & 2 & 3 & 4 & 5 & 6 & 7 & 8 \\
\hline$\tilde{b}_{k, l}$ & if & 0.6000 & 1.5000 & 3.0000 & 0.0522 & 0.1195 & 0.1704 & 0.3803 & 0.2160 \\
& if & 0.8000 & 2.0000 & 4.0000 & 0.0638 & 0.1156 & 0.2254 & 0.2970 & 0.2453 \\
& $s$ & 2.0000 & 6.0000 & 9.0000 & 0.6750 & 0.1142 & 0.2269 & 0.2669 & 0.2423 \\
& ic & 0.8000 & 2.5000 & 5.0000 & 0.0638 & 0.1156 & 0.2254 & 0.2970 & 0.2453 \\
& $j c$ & 0.6000 & 2.0000 & 4.0000 & 0.6750 & 0.1142 & 0.2269 & 0.2669 & 0.2423 \\
\hline$\tilde{\omega}_{k, l}$ & if & 0.9000 & 0.9800 & 0.9999 & 0.0751 & 0.0937 & 0.4130 & 0.3444 & 0.5442 \\
& if & 0.9000 & 0.9800 & 0.9999 & 0.1671 & 0.2095 & 0.5736 & 0.4751 & 0.6318 \\
& $s$ & 0.1834 & 0.1834 & 0.1834 & 0.1932 & 0.2406 & 0.5876 & 0.4751 & 0.6389 \\
& ic & $*$ & $*$ & $*$ & 0.1671 & 0.2095 & 0.5736 & 0.4751 & 0.6318 \\
& jc & $*$ & $*$ & $*$ & 0.1932 & 0.2406 & 0.5876 & 0.4751 & 0.6389 \\
\hline$\tilde{g}_{k, l}$ & if & 0.5000 & 0.6000 & 0.6500 & 0.0815 & 0.1228 & 0.3952 & 0.3156 & 0.6574 \\
& jf & 0.5000 & 0.6000 & 0.6500 & 0.1132 & 0.1909 & 0.4894 & 0.4442 & 0.7683 \\
& $s$ & 0.5000 & 0.6000 & 0.6500 & 0.1239 & 0.2158 & 0.5112 & 0.4897 & 0.7848 \\
& ic & 0.5000 & 0.6000 & 0.6500 & 0.1132 & 0.1909 & 0.4894 & 0.4442 & 0.7683 \\
& $j c$ & 0.5000 & 0.6000 & 0.6500 & 0.1239 & 0.2158 & 0.5112 & 0.4897 & 0.7848 \\
\hline
\end{tabular}

* In these cases the single scattering albedo is calculated according to terms 4 and 5 of Eq. (20).

The single scattering albedo $\omega_{k}$ is calculated differently for the long wave range and the short wave range. For wavelength intervals $1-3 \omega_{k}$ is given by:

$\omega_{k}=\tilde{\omega}_{k, i} \cdot \mathrm{f}_{i f}+\tilde{\omega}_{k, j} \cdot \mathrm{f}_{j f}+\tilde{\omega}_{k, s} \cdot \mathrm{f}_{s}+\left(2.6278 \cdot \mathrm{sf}_{i c}+1\right)^{-1.8048} \cdot \mathrm{f}_{i c}$

$+\left(2.0611 \cdot \mathrm{sf}_{j c}+1\right)^{-1.4309} \cdot \mathrm{f}_{j c}$,

and for wavelength intervals $4-8$ by:

$\omega_{k}=\sum_{l} \tilde{\omega}_{k, l} \cdot f_{l}$.

The asymmetry factors $g_{k}$ of the individual wavelength intervals are calculated by:

$g_{k}=\sum_{l} \tilde{g}_{k, l} \cdot f_{l}$.

$\mathrm{sf}_{i c}$ and $\mathrm{sf}_{j c}$ are the soot fractions of modes $i c$ and $j c$, respectively. The factor $\mathrm{f}_{l}$ gives the mass fraction of the respective mode 1 related to the total aerosol mass including water. In Table 3 the $\tilde{b}_{k, l}, \tilde{\omega}_{k, l}$, and $\tilde{g}_{k, l}$ are given for each wavelength interval and respective mode. The method we applied here (Eqs. 21 and 22) is a simplification as we calculated the single scattering albedo and the asymmetry parameter by weighting the values of the individual modes by their mass fraction. We also calculated the single scattering albedo by weighting the contributions of each mode with their corresponding extinction coefficient and the asymmetry factor by weighting with its corresponding extinction coefficient and single scattering albedo. On average the deviations were in the order of a few percent.
In our case the mass fraction of the coarse mode is very low, therefore the coarse mode does not contribute remarkably to the extinction and was neglected in these simulations. We looked for AERONET data at the station Karlsruhe (Germany) and found for both episodes (LC and HC) a small contribution $(<15 \%)$ of the coarse mode to the aerosol optical depth. This might be different in the southern part of the model domain where mineral dust contributes a lot to the total aerosol load.

\subsection{Photolysis frequencies}

Photochemistry is influenced by the radiative fluxes in the atmosphere. The photolysis frequencies are required at each grid point due to the highly variable spatial and temporal distribution of clouds and aerosols. As the detailed calculation of the photolysis frequencies for the individual species is very time consuming, we have developed a new parameterisation combining a detailed radiation scheme with an efficient two-stream scheme. In contrast to existing procedures, which on one hand cannot account for changes in e.g. cloud cover and on the other hand need additional time consuming radiation calculations (e.g. Wild et al., 2000; Landgraf and Crutzen, 1998), this parameterisation uses the existing efficient radiation calculations as described above. The parameterisation consists of two steps. Step one is an a priori calculation of vertical profiles for the shortwave actinic flux $I_{A}^{*}$ for wavelength band 3 and the photolysis frequencies $J_{i}^{*} . J_{i}^{*}$ is achieved with the detailed radiation scheme STAR (System for Transfer of Atmospheric Radiation; Ruggaber et al., 1994) and the shortwave actinic flux $I_{A}^{*}$ is calculated 


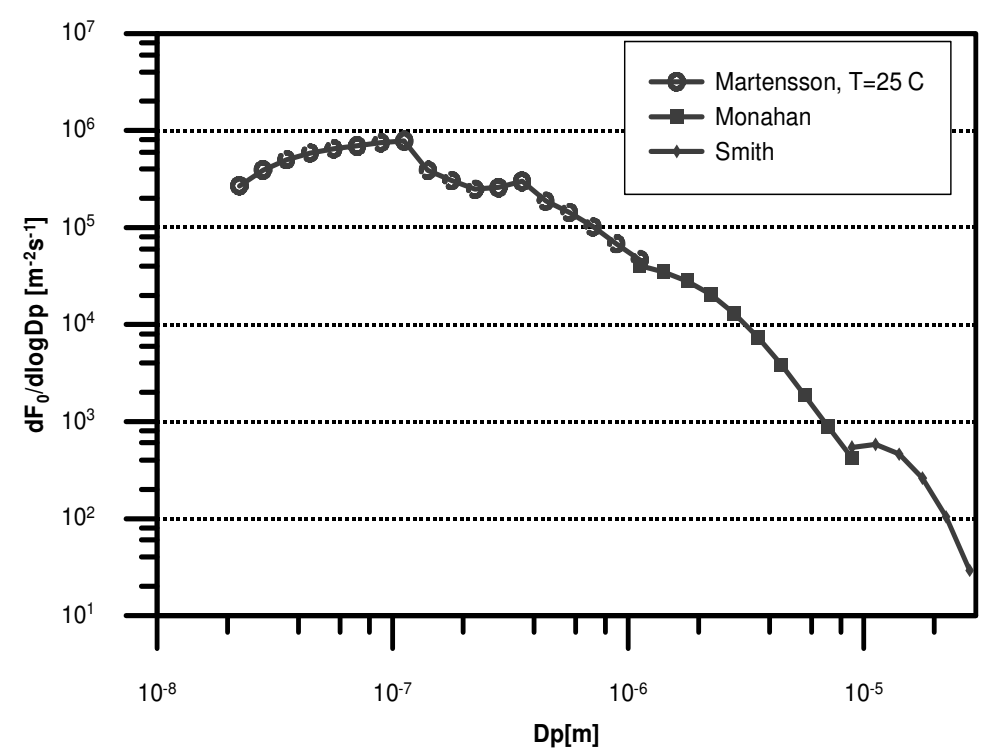

Fig. 2. The three parameterizations describing flux of sea-salt particles per area of bubbles and second for chosen intervals for a sea surface temperature of $25^{\circ} \mathrm{C}$ and a wind speed of $9 \mathrm{~m} \mathrm{~s}^{1}$, Lundgren (2006).

with the radiation code GRAALS. These calculations are carried out for a set of solar zenith angles for cloud free conditions and for standard profiles of the aerosol optical depth. Since GRAALS is a two-stream scheme the actinic flux is calculated by:

$I_{A}=\frac{1}{\mu_{0}} E_{\mathrm{dir}}+2 E_{\mathrm{diff}}$

$E_{\text {dir }}$ is the direct solar irradiance, $E_{\text {diff }}$ is the diffuse irradiance, and $\mu_{0}$ is the cosine of the zenith angle. In the second step the online calculation of the actual profiles of the shortwave actinic flux $I_{A}$ is carried out. By dividing the actual actinic flux by the pre-calculated one, the relative change is determined. The most important factor for the vertical profile of the actinic flux are clouds. For overcast situations the impact of clouds on the actinic flux is nearly wavelength independent in the desired wavelength band (Crawford et al., 2003). Hence, the pre-calculated vertical profiles of the individual photolysis frequencies are used to calculate $J_{i}(\mathrm{z})$.

$J_{i}(\mathrm{z})=J_{i}^{*}(\mathrm{z})\left(\frac{I_{A}(\mathrm{z})}{I_{A}^{*}(\mathrm{z})}\right)$

\subsection{Emissions}

\subsubsection{Anthropogenic and biogenic emissions}

The anthropogenic emissions were pre-calculated with a spatial resolution of $14 \times 14 \mathrm{~km}^{2}$ and a temporal resolution of one hour. The weekly cycle of the emissions is not taken into account. The anthropogenic emission data account for traffic emissions, emissions by large point sources and area sources such as households and industrial areas. The method used to determine these emissions is described in Pregger et al. (2007). Emissions of the gases $\mathrm{SO}_{2}, \mathrm{CO}, \mathrm{NO}_{\mathrm{x}}, \mathrm{NH}_{3}$, and 32 individual classes of $\mathrm{VOC}$, and the particle classes $\mathrm{PM}_{10}$ and EC1 are treated. PM denotes particulate matter and EC elemental carbon. $\mathrm{PM}_{10}$ is emitted into the anthropogenic coarse mode $\mathrm{c}$ with an initial median diameter of $6 \mu \mathrm{m}$ and EC1 into the pure soot mode s with an initial diameter of $0.17 \mu \mathrm{m}$. While the anthropogenic emissions are pre-calculated the biogenic VOC emissions are calculated as functions of the land use data, the modelled temperatures and the modelled radiative fluxes (Vogel et al., 1995). For the parameterisation of the NO emissions from the surface a modified scheme of Yienger and Levy (1995) is used (Ludwig et al., 2001).

\subsubsection{Sea salt emissions}

The emission of sea salt depends on the wind speed and on the sea water temperature and is calculated using a combination of three individual parameterisations for three individual size ranges (Lundgren, 2006). The parameterisation of Mårtensson et al. (2003) is chosen for particles with a dry particle diameter of $0.02 \mu \mathrm{m}<\mathrm{D}_{p}<1 \mu \mathrm{m}$. For $1 \mu \mathrm{m}<\mathrm{D}_{p}<9 \mu \mathrm{m}$, the parameterisation of Monahan et al. (1986) is used and the parameterisation of Smith et al. (1993) is used to describe the flux of particles with a dry particle diameter of $9 \mu \mathrm{m}<\mathrm{D}_{p}<28 \mu \mathrm{m}$. This is illustrated in Fig. 2.

For describing the initial lognormal distribution of sea salt the mode diameter and standard deviation given in Table 4 are implemented. The values are taken from measurements by O'Dowd et al. (1997), except for the standard deviation of 


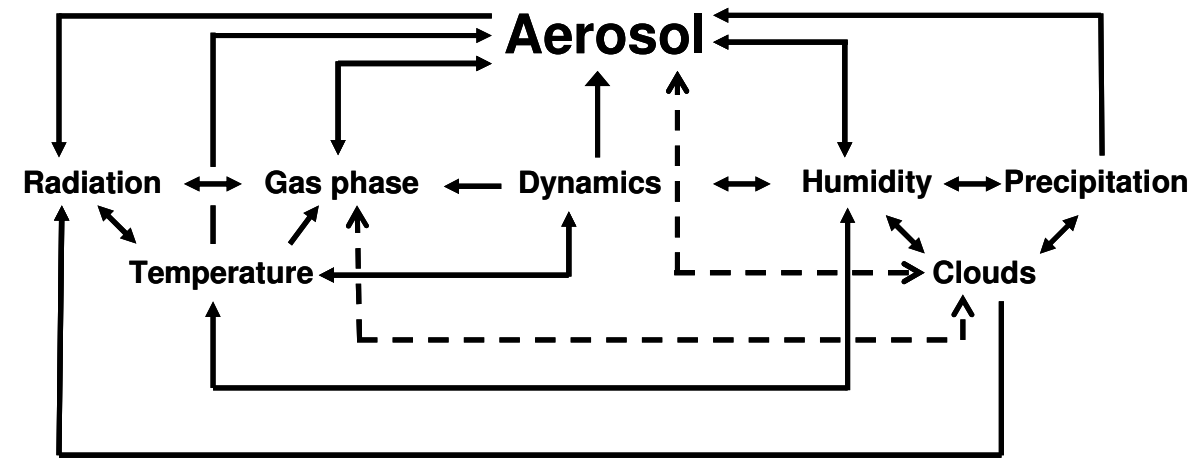

Fig. 3. Feedback processes that are included in the model runs. The dashed lines indicate interactions that are not taken into account.

Table 4. Initial median diameter and standard deviation for the three sea salt modes respectively.

\begin{tabular}{lcc}
\hline Particle Size Mode & Mode Diameter $[\mu \mathrm{m}]$ & Standard deviation \\
\hline Film & 0.2 & 1.9 \\
Jet & 2 & 2 \\
Spume & 12 & 1.7 \\
\hline
\end{tabular}

the third mode which has been modified with the assumption that large particles have a short residence time in the atmosphere.

\subsubsection{Mineral dust emissions}

The emissions of mineral dust depend on the friction velocity and on the surface conditions. Mineral dust particles are represented by three modes with initial diameters of 1.5, 6.7 and $14.2 \mu \mathrm{m}$. A detailed description of the dust emissions module is given in Vogel et al. (2006).

\subsection{Sedimentation and deposition}

The sedimentation and dry deposition of the aerosol species is treated according to Binkowski and Shankar (1995) and Ackermann et al. (1998, and references therein). The washout of the aerosol particles depends on their size distribution and the size distribution of the rain droplets. A detailed description of the parameterisation that is used in COSMO-ART is given in Rinke (2008).

\section{Results}

COSMO-ART is applied to quantify the impact of soot and secondary aerosols via the modification of atmospheric radiation on the state of the atmosphere over Europe for two episodes. Direct interactions of the particles with cloud microphysics are currently excluded. The modification of the radiative fluxes caused by the aerosol particles initialises a number of feedback mechanisms starting with changes in temperature (Fig. 3). Thereafter, the wind, turbulence, humidity, and cloud distributions are modified. Additionally there is an impact on the precipitation which leads to a modification of the washout resulting in another feedback mechanism. The chemical composition of the gaseous and particulate components is modified by these changes. Changes in radiation fluxes due to the aerosol particles also influence the photolysis frequencies and thus, the concentrations of the gases and the chemical composition of the aerosol are modified. An overview describing the feedback mechanisms that are treated in this application of COSMO-ART is given in Fig. 3.

The simulation domain includes a large part of Europe and northern Africa (Fig. 6). We used a horizontal grid size of $0.125^{\circ}(\sim 14 \mathrm{~km})$ in both horizontal directions and 40 vertical layers up to a height of $20 \mathrm{~km}$. The meteorological initial and boundary conditions are achieved from the IFS model of ECMWF. Clean air conditions are prescribed for the gaseous and the aerosol variables. The analyses are used to update the boundary conditions every six hours. We are applying the standard COSMO procedure including a buffer zone at the lateral boundaries. The gaseous and the particulate species are treated at the lateral boundaries in the same way as the atmospheric variables are treated. For the calculation of the biogenic VOC emissions we used land use data provided by the Joint Research Center at Ispra (http: //www-tem.jrc.it/glc2000/).

We simulated two situations which especially differed in average cloud cover. The first episode (LC) lasted from 28 August until 1 September 2005 and was characterized by nearly cloud free conditions, i.e. a low amount of clouds. Figure 4 shows the surface pressure and the $500 \mathrm{hPa}$ geopotential for the last three days of the episode. A stable surface near high-pressure system with weak gradients over Germany and a ridge over Central Europe prevailed in the period from 29 August until 1 September 2005. Temperatures over Germany reached values above $30^{\circ} \mathrm{C}$. In Fig. 5 (left) the 

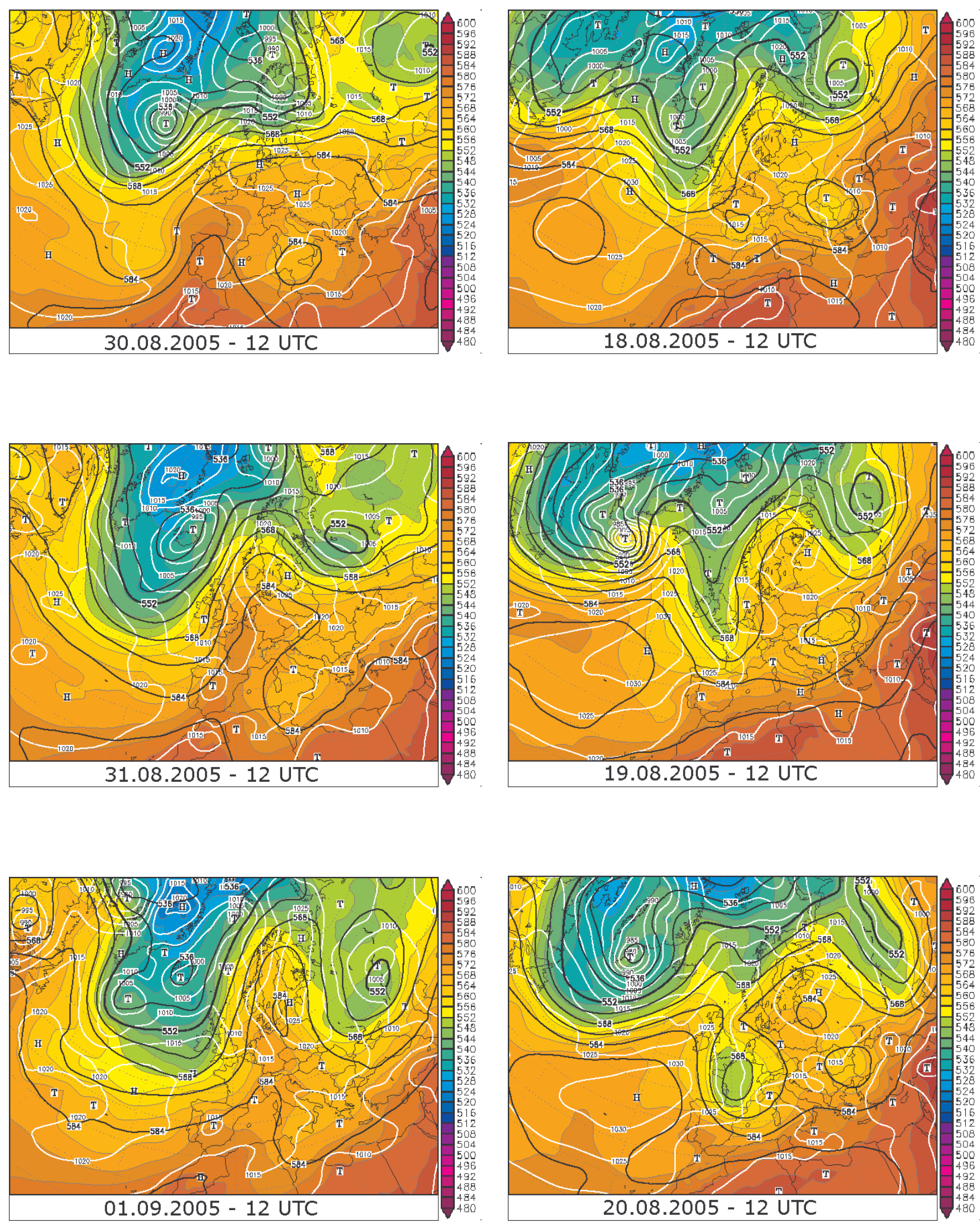

Fig. 4. Synoptic maps for episodes LC (left) and HC (right); $500 \mathrm{hPa}$ geopotential in gpdm (black contours), surface pressure in hPa (white contours) and relative topography in gpdm (colours); ${ }^{{ }^{C}}$ www.wetter3.de. 

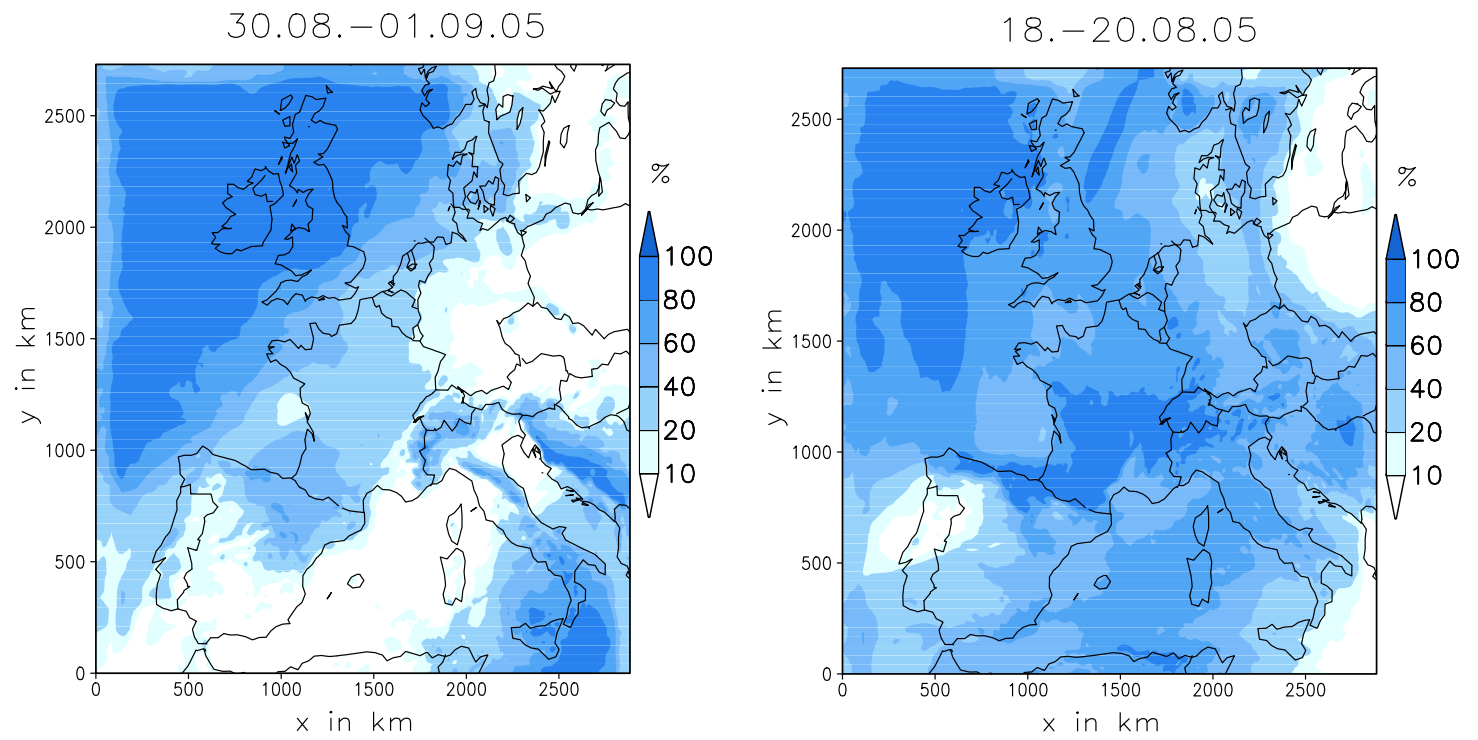

Fig. 5. Mean cloud cover for episodes LC (left) and HC (right).

average cloud cover for the corresponding period simulated with COSMO-ART is illustrated. The mean cloud cover was less than 20\% over Germany, Poland, the Czech Republic, Austria, France, and Southern Spain during this episode.

The second episode (HC) lasted from 16 August until 20 August 2005. During that episode rather cloudy conditions prevailed. In the beginning of the episode the meteorological situation was characterized by a ridge over France and Great Britain, with less clouds and easterly winds. During the following days a high-level trough approached Europe and intensified. On the front side of the trough a depression developed over France and moved on in a north-eastern direction during the next days. This development yielded cloudy conditions and westerly winds for large parts of Europe from the 18 until the end of the episode. During the first four days the daily maximum temperature mostly exceeded $25^{\circ} \mathrm{C}$. On the last day of the episode a change in air mass from warm polluted air to cooler maritime air occurred over France and Germany due to a frontal system passage.

For each case we carried out two sets of simulations. First a reference run $(\mathrm{R})$ was carried out neglecting the feedback mechanisms between the aerosol particles and the atmosphere. In the second model run $(\mathrm{F})$ the feedback mechanisms initialized by the modification of the radiative fluxes by the aerosol particles were enabled. Two days of simulation time were used for the spin up of the model before the feedback processes were switched on.

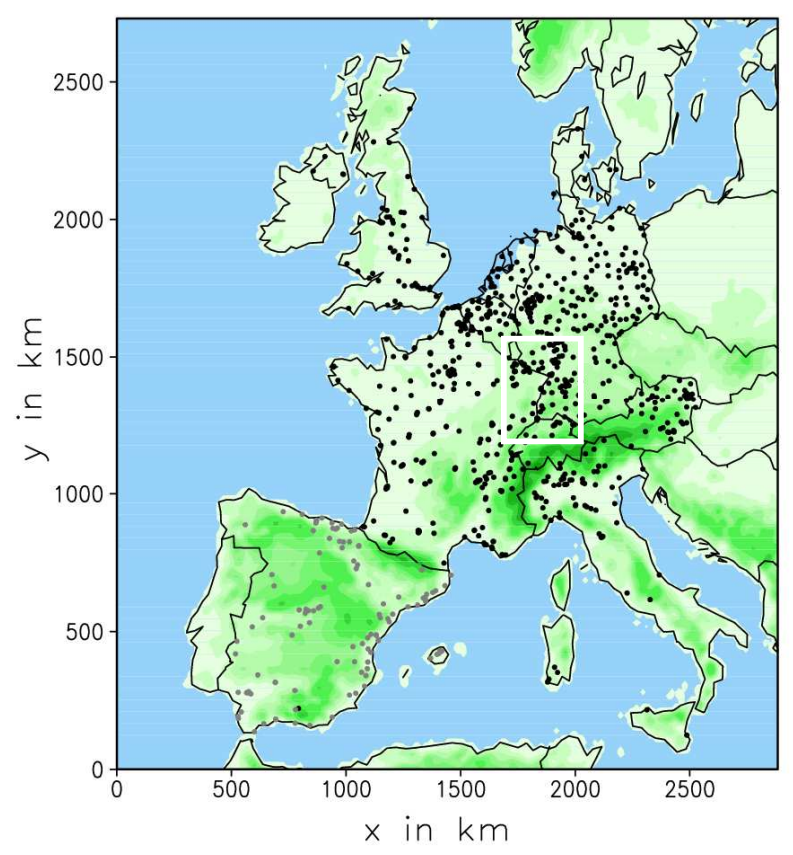

Fig. 6. Location of the surface based stations that were used for comparison of measured and simulated $\mathrm{PM}_{10}$.

\subsection{Comparison with observations}

The results of simulation $\mathrm{F}$ were compared with observations for each of the episodes. Daily mean $\mathrm{PM}_{10}$ concentration data were used from more than 731 stations classified as rural. Their respective locations are given in Fig. 6 (EEA, Copenhagen, 2008). We excluded the measurements 

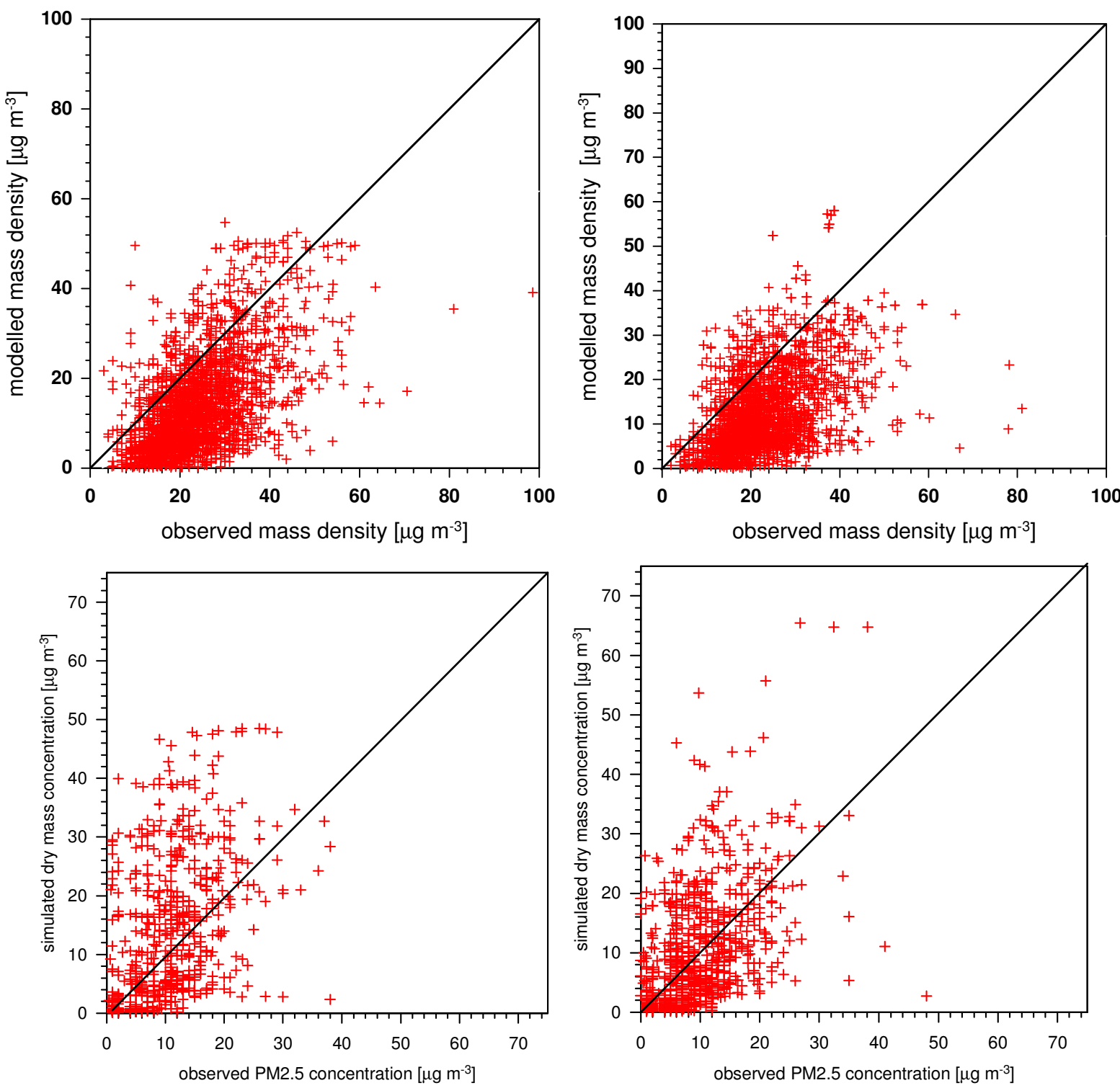

Fig. 7. Top: Simulated dry aerosol mass concentration (coarse mode included) and observed $\mathrm{PM}_{10}$ concentrations for episodes LC (left) and HC (right). Bottom: Simulated dry aerosol mass concentration (coarse mode excluded) and observed $\mathrm{PM}_{2.5}$ concentrations for episodes LC (left) and HC (right).

of the stations in Spain since the measured concentrations were much higher than the simulated ones, even for remote stations. A possible reason could be large contributions of mineral dust not only from the Saharan desert but also from local sources in Spain, or from local biomass burning. Neither of these emission sources was taken into account in our model runs and these stations were thus excluded in the comparisons. Figure 7 (top) shows simulated daily mean dry mass concentrations and observed daily $\mathrm{PM}_{10}$ concentrations for the stations that are depicted in Fig. 6. The average $\mathrm{PM}_{10}$ concentration of all stations is $23 \mu \mathrm{g} \mathrm{m}^{-3}$ and the simulated one is $13 \mu \mathrm{g} \mathrm{m}^{-3}$. That means that the simulated concentrations were on average $40 \%$ lower than the observed ones. For episode $\mathrm{HC}$ the average $\mathrm{PM}_{10}$ concentration of all stations is $21 \mu \mathrm{m}^{-3}$ and the simulated one is $12 \mu \mathrm{g} \mathrm{m}^{-3}$. The simulated concentrations were again on average $40 \%$ lower than the observed concentrations. The underestimation of the observations is comparable to the results of Grell et al. (2005). The correlation is lower than those documented by Stern et al. (2008) and Sartelet et al. (2007) but in those cases model simulations were performed for longer time periods. Reasons for the underestimation could be lacking emissions of $\mathrm{PM}_{10}$ and an underestimation of the organic particle fraction. Furthermore we prescribed clean air at the 
boundaries of our model domain which may also have contributed to the underestimated simulated concentrations compared to the observed concentrations. This shortcoming will be avoided in the future by the supplying the model system with boundary conditions from global scale models.

We also compared the simulated dry aerosol mass density and the observed $\mathrm{PM}_{2.5}$ concentrations (Fig. 7, bottom). Although the scatter of the data is comparable to the results for $\mathrm{PM}_{10}$ the absolute values are now in a better agreement. The average values of simulated and observed mass concentrations are now $13.6 \mu \mathrm{g} \mathrm{m}^{-3}$ and $10.6 \mu \mathrm{g} \mathrm{m}^{-3}$ in case $\mathrm{LC}$ and $10.1 \mu \mathrm{g} \mathrm{m}^{-3}$ and $9.5 \mu \mathrm{g} \mathrm{m}^{-3}$ in case $\mathrm{HC}$.

For episode HC we carried out additional simulations with the nested version of COSMO-ART. The model domain for this simulation is shown in Fig. 6. The horizontal grid size for the smaller domain was $0.0625^{\circ}(\sim 7 \mathrm{~km})$. Figure 8 shows diurnal cycles of $\mathrm{NO}_{2}$ and $\mathrm{PM}_{10}$ for the monitoring station Eggenstein (Landesanstalt für Umwelt, Messungen und Naturschutz Baden-Württemberg, Germany). This station is located close to a four lane radial highway with high traffic during the morning and the evening hours. In case of $\mathrm{NO}_{\mathrm{x}}$ the model system is able to reproduce the observations with the exception of individual peaks. The simulated and measured $\mathrm{NO}_{\mathrm{x}}$ concentrations averaged over four days are almost identical $\left(29 \mu \mathrm{g} \mathrm{m}^{-3}\right)$. Again, the model underestimates the $\mathrm{PM}_{10}$ concentrations by a factor of two (measured: $23.8 \mu \mathrm{g} \mathrm{m}^{-3}$, simulated: $10.4 \mu \mathrm{g} \mathrm{m}^{-3}$ ).

As COSMO-ART calculates the extinction coefficient at each grid point and at each time step it is possible to compare the simulated optical depth with those obtained from satellite data. Figure 9 shows the observed and the calculated aerosol optical depth at 1 September 2005 for the time period when MODIS-Terra (Acker and Leptoukh, 2007) passed over the model domain. The observed spatial pattern is in agreement in the central part of the model domain. Larger deviations are found in the south-eastern part. This is caused by the assumption of clean air at the lateral boundaries and the neglecting of mineral dust.

\subsection{Feedback of aerosols and the state of the atmosphere}

Bäumer and Vogel (2007) have detected weekly cycles for atmospheric variables such as temperature and cloud cover over Germany. They also found distinct weekly cycles in the aerosol optical depth for several stations located in Germany and other European countries (Bäumer et al., 2008). This raises the question if the observed weekly cycles of the atmospheric variables can be attributed to the weekly cycles of the aerosol concentrations. The model results that we present here are a first step to answer this question. We used COSMO-ART to quantify the effect of the soot and natural and anthropogenic secondary aerosol particles on the state of the atmosphere. This is done by comparing the results of model runs $\mathrm{R}$ and $\mathrm{F}$. The aerosol concentrations show a high
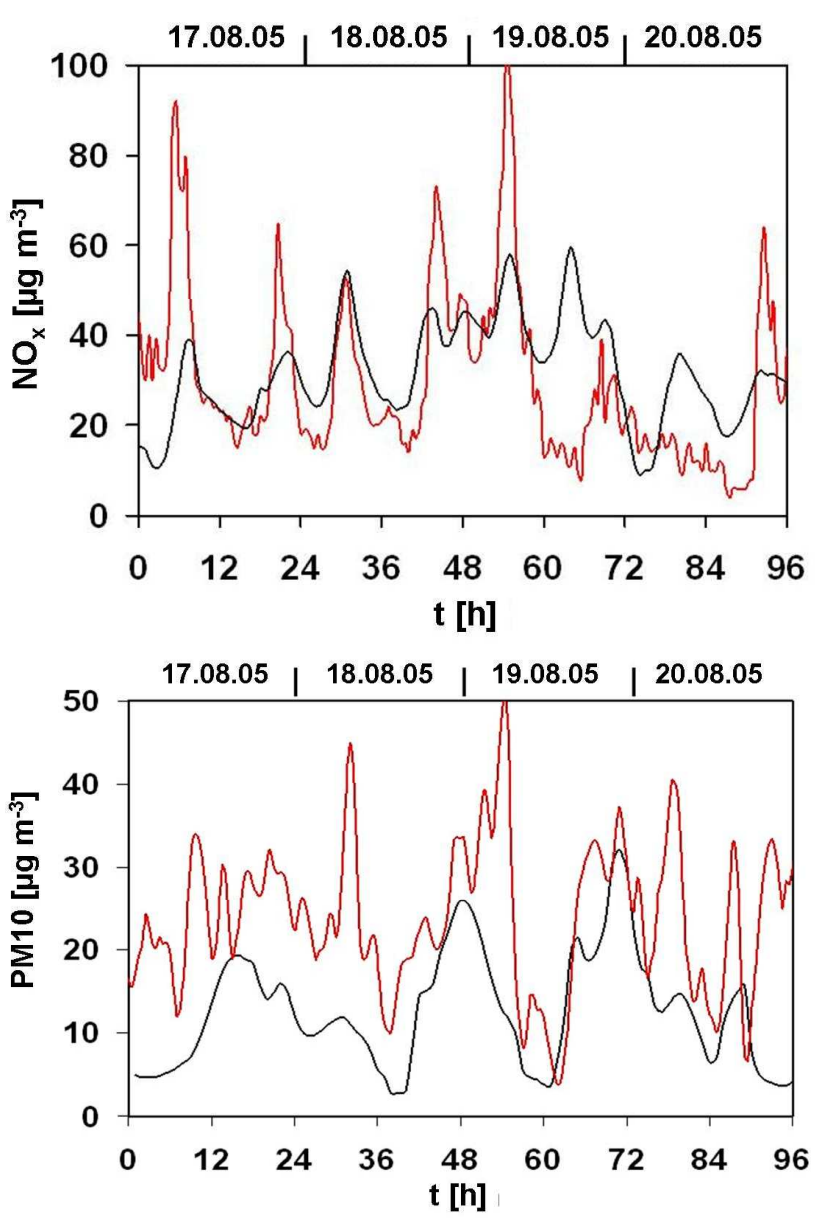

Fig. 8. Simulated (black) and observed (red) daily cycles of $\mathrm{NO}_{\mathrm{x}}$ and $\mathrm{PM}_{10}$ at Eggenstein.

spatial and temporal variation for both episodes (see supplemental material: http://www.atmos-chem-phys.net/9/8661/ 2009/acp-9-8661-2009-supplement.pdf). Consequently the changes in the radiative fluxes caused by the aerosol particles are also highly variable. In order to get a more general picture we averaged the model results over the last three days of each episode (LC, HC).

In Fig. 10a the horizontal distribution of the averages over three days of the dry aerosol mass concentration is shown for the lowest model layer for episode LC (left) and HC (right). For the episode LC high aerosol concentrations are simulated over the Po valley, the southern part of the North Sea, the northern part of France, Belgium, Luxemburg and the Netherlands. The aerosol concentrations show no spatial correlation with the emissions. This is caused by the nonlinearity of the chemical and physical processes that are involved in the formation of the secondary aerosol. 
Also for episode HC high dry aerosol mass concentration is simulated for the southern part of the North Sea, Belgium, the Netherlands and the north-western part of Germany. As in episode LC high aerosol concentrations are simulated in the Po valley. For the HC episode high mean aerosol concentrations are also simulated in the south-eastern part of Germany.

The modification of the radiative fluxes depends on the water content of the aerosol (see Sect. 2.4). Figure 10b illustrates the spatial distribution of the wet aerosol mass concentration. Again averages over three days are shown for the LC (left) and HC (right) episodes. The highest values are approximately $370 \mu \mathrm{g} \mathrm{m}^{-3}$ in case $\mathrm{LC}$ and $450 \mu \mathrm{g} \mathrm{m}^{-3}$ in case HC. A comparison of the dry mass concentration with the wet mass concentration shows differences in the pattern of the spatial distributions. For the LC episode, especially in the part of the Po valley, where high dry aerosol mass concentration was simulated, we observe a modified distribution in the wet mass concentration with two maxima in the north and the south. This is caused by higher relative humidity in the mountainous regions (see supplemental material: http://www.atmos-chem-phys.net/9/8661/2009/ acp-9-8661-2009-supplement.pdf). Larger differences in the spatial pattern are also found over England. While the highest wet mass concentrations are found over land, the highest dry mass occurs over the North Sea. The reason for this is a frontal passage during episode $\mathrm{LC}$ which is connected to a band of high relative humidity. This band passes over Great Britain during the episode and reaches France at 1 September. In Germany, where low relative humidity prevails between 30 August and 1 September, the spatial distributions of the dry and the wet aerosol concentrations are similar. The aerosol water content is influenced by the nitrate content, which is strongly dependent on the temperature. As the temperature was only changing slightly the spatial distribution of the wet and the dry aerosol mass concentration looks similar over Germany. This is not the case in the western part of the model domain e.g. above Great Britain due to temperature changes.

Figure 10c shows the difference in global radiation $\left(\Delta \mathrm{E}_{G}=\mathrm{E}_{G}(\right.$ run $\mathrm{F})-\mathrm{E}_{G}($ run R) $)$ at the surface, averaged over the last three days of each episode (LC left, HC right). For the episode LC the spatial patterns of the wet aerosol concentration (Fig. 10b) and $\Delta \mathrm{E}_{G}$ (Fig. 10c) are similar. In general, the aerosol leads to a reduction in the global radiation in the range of $10 \mathrm{~W} \mathrm{~m}^{-2}$. In some areas the reduction is even larger with maximum values of $50 \mathrm{~W} \mathrm{~m}^{-2}$. Although averages over three days are presented here there are areas where $\Delta \mathrm{E}_{G}$ shows a spotty behaviour e.g. in the south-eastern part of the model domain. The increase in global radiation in such cases is due to changes in cloud properties (e.g. cloud water content) that are initialized by the radiative effect of the aerosol particles on the thermodynamics of the atmosphere. These changes in cloud properties superpose the effects of the aerosol. The radiative impact of the aerosol is modified by feedback processes of clouds although effects of aerosol particles on cloud microphysics are neglected in this study.

In the south-eastern part the spotty pattern can be explained by a spatial shift of clouds. When no clouds are present, as over Germany, only negative values of $\Delta \mathrm{E}_{G}$ occur (Fig. 10c). Furthermore, temperature and other meteorological variables are modified through the feedback mechanism (Fig. 3).

During episode HC larger areas of the model domain are covered by clouds. Consequently, the correlation between the aerosol concentration (Fig. 10b) and the $\Delta \mathrm{E}_{G}$ (Fig. 10c) decreases. In the eastern part of Germany where high aerosol concentrations are simulated $\Delta \mathrm{E}_{G}$ is very low and in some areas even positive. However, in areas with fewer clouds as the North Sea and the Netherlands negative values of $\Delta \mathrm{E}_{G}$ and high aerosol concentrations coincide.

Figure 10d shows the corresponding averages over three days of the temperature change $(\Delta \mathrm{T}=\mathrm{T}($ run $\mathrm{F})-\mathrm{T}($ run $\mathrm{R}))$ at $2 \mathrm{~m}$ height for both episodes. For episode LC (left) a decrease in temperature is obvious at those grid points where the global radiation is reduced by the aerosol particles. This is not the case in the areas where clouds are present. $\Delta \mathrm{T}$ is found in the range between $-1 \mathrm{~K}$ and $+1 \mathrm{~K}$.

As could already be expected from the changes in global radiation (Fig. 10c) the correlation for episode $\mathrm{HC}$ of the aerosol concentration and the changes in temperature is small (Fig. 10d). A temperature increase is simulated in the southeastern part of Germany where high aerosol concentrations are simulated but the changes in global radiation are small. This behaviour is a result of several nonlinear feedback mechanisms and cannot be addressed to a single process. $\Delta \mathrm{T}$ is seen between $-1 \mathrm{~K}$ and $+1.5 \mathrm{~K}$ for this episode.

\subsection{Aerosol effects on the $2 \mathrm{~m}$ temperature above Germany}

In the following we concentrate on the model results for Germany. As can be seen in Fig. 5 Germany was almost cloud free for three days during episode LC and had a high cloud cover during episode HC. Figure 11 gives the aerosol wet mass concentration in the lowest model layer versus the simulated differences of the $2 \mathrm{~m}$ temperature for runs $\mathrm{F}$ and $\mathrm{R}$ for each episode. It is obvious that for episode LC the aerosol the changes in temperature and the wet mass concentration are correlated quite well (Fig. 11, left). This is not the case for episode HC. In this case the temperature change is no longer correlated with the wet mass concentration (Fig. 11, right). The nonlinearity is mainly caused by changes in cloud properties due to changes in the dynamics that are initialised by the modification in radiation.

Several previous studies based on observations have focused on the weekly cycles of meteorological variables. Bäumer and Vogel (2007) found a weekly cycle of the mean temperature anomaly of about $0.2 \mathrm{~K}$ for an average over 15 years and 12 stations distributed over Germany. Other 

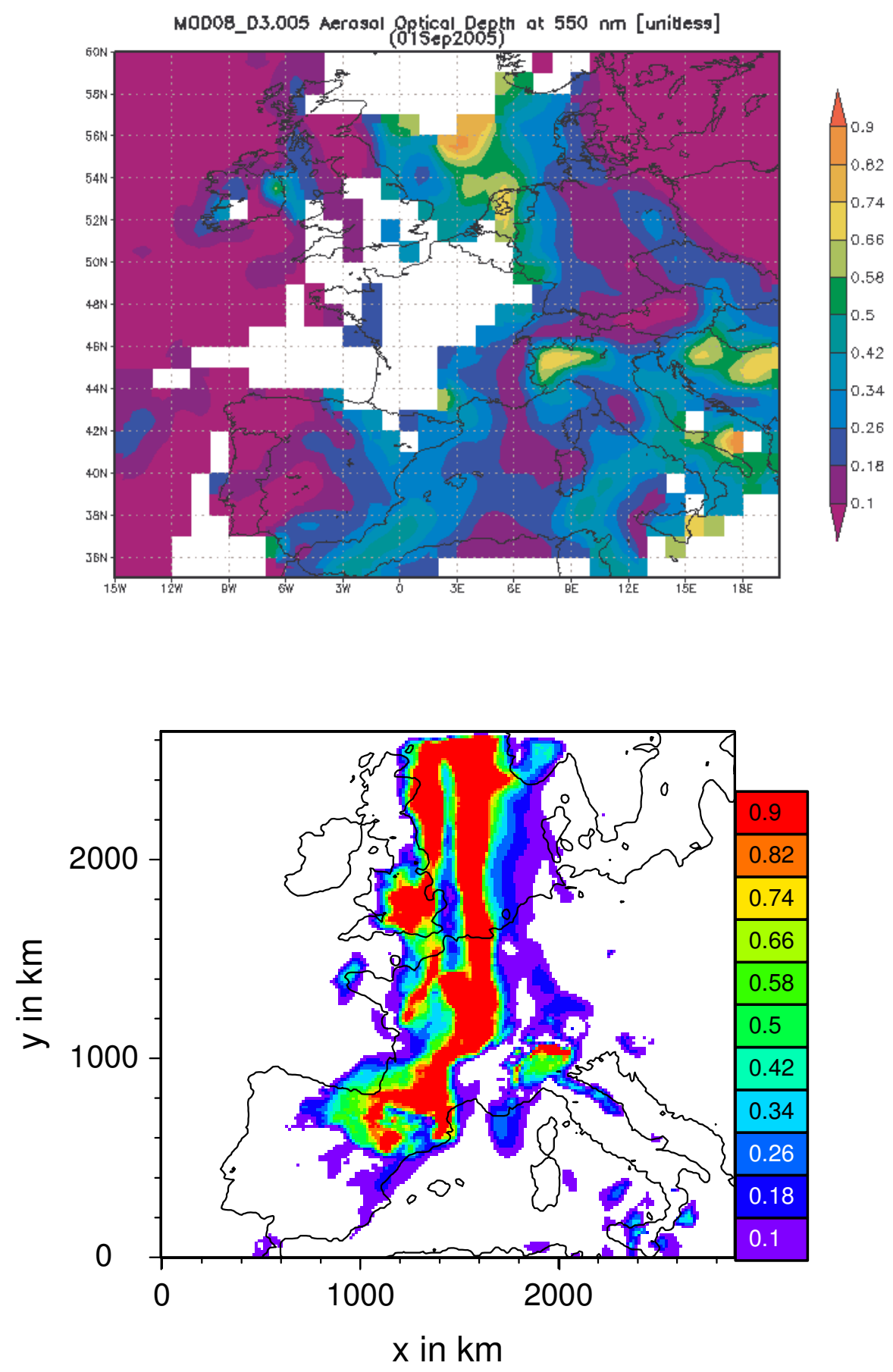

Fig. 9. AOD derived from MODIS terra satellite (top) and simulated AOD (bottom) at 1 September 2005, 11:00 UTC.

studies focused on the weekly cycle of the daily temperature range (Forster and Solomon, 2003; Gong et al., 2006). The daily temperature range is the difference between the maximum and the minimum temperature at a certain day. It has been speculated that these weekly cycles are caused by the weekly cycle of the aerosol concentration. A weekly cycle of the aerosol optical depth was found for stations distributed over Europe by Bäumer et al. (2008).
As our simulations were only carried out for two episodes and we neglected the feedback of the aerosol particles with the cloud microphysics it is not possible to compare our temperature difference with those that were determined from observations for a period of 15 years. Nevertheless it is quite interesting to compare the magnitude of our simulated differences in temperature and daily temperature range with the observed weekly cycles. 

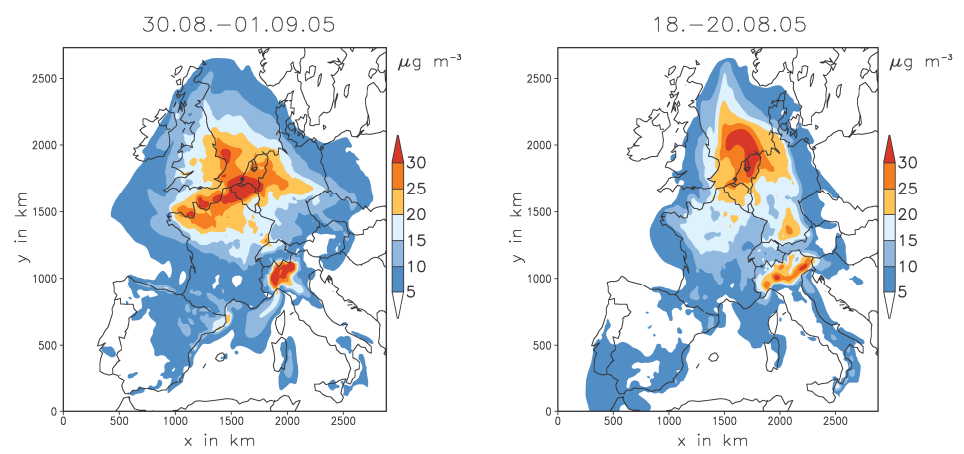

a)
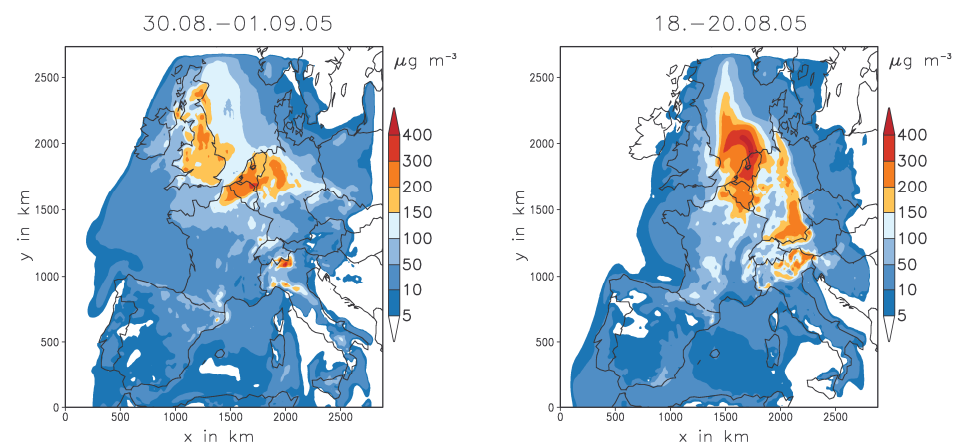

b)
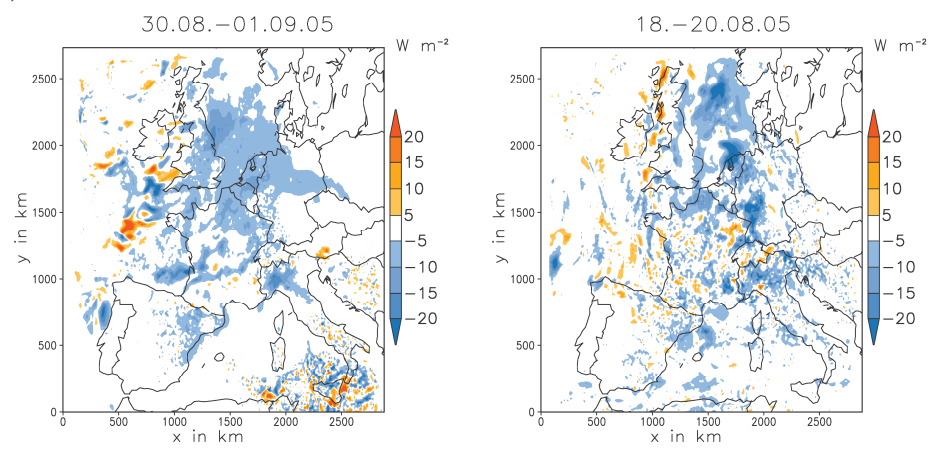

c)
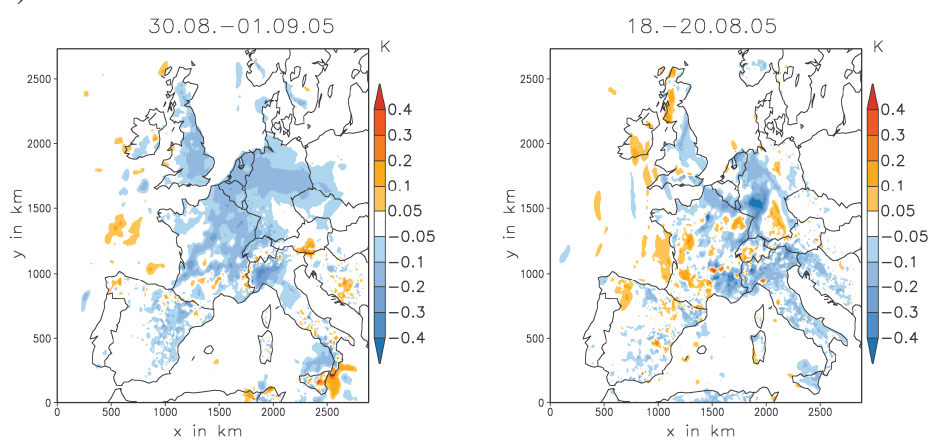

d)

Fig. 10. Simulated averages over three days of aerosol dry mass concentration (a), wet mass concentration (b), difference in global radiation (c), and difference in $2 \mathrm{~m}$ temperature (d). Results are shown for episodes LC (left) and HC (right). 

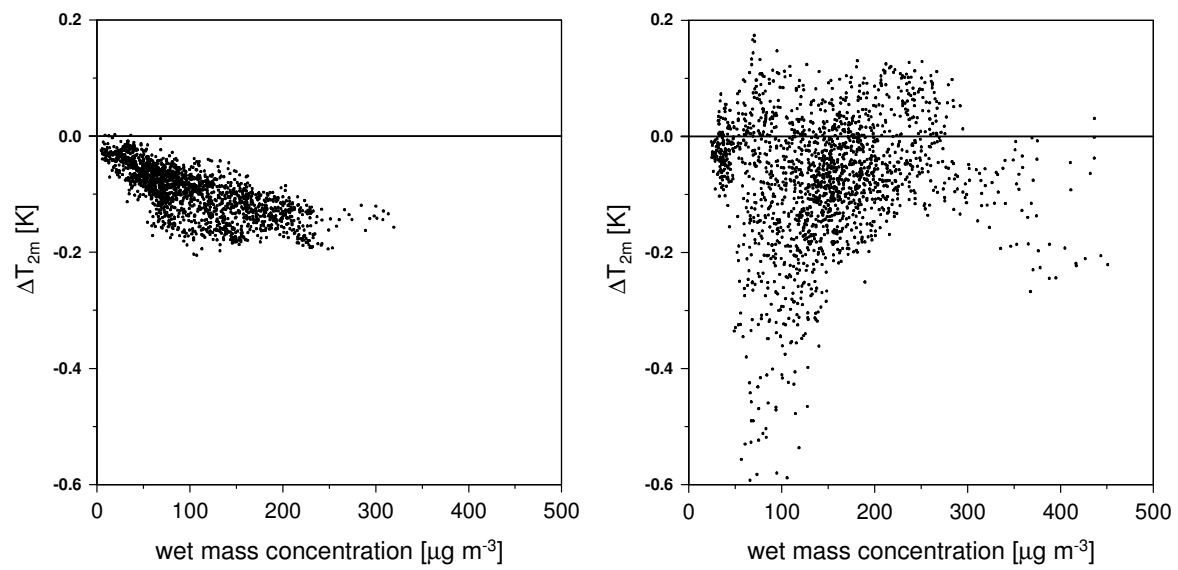

Fig. 11. Simulated change in $2 \mathrm{~m}$ temperature and wet mass concentration. Each data point gives the three day average (left: episode LC, right: episode $\mathrm{HC}$ ).

Table 5. Averages over three days of AOD, $\Delta \mathrm{E}_{G}$ and $\Delta \mathrm{T}$ for the sub domain that covers Germany for cases LC and HC.

\begin{tabular}{lcc}
\hline & $\mathrm{LC}$ & $\mathrm{HC}$ \\
\hline $\mathrm{AOD}$ & 0.172 & 0.590 \\
$\Delta \mathrm{E}_{G}$ in $\mathrm{W} \mathrm{m}^{-2}$ & -5.43 & -6.01 \\
$\Delta \mathrm{T}$ in $\mathrm{K}$ & -0.10 & -0.08 \\
\hline
\end{tabular}

We evaluate the model results in detail for a sub domain that covers Germany. The results of this evaluation are summarized in Table 5. The averages over three days of the aerosol optical depth (AOD) for the model runs $\mathrm{F}$ and $\mathrm{R}$ is 0.17 for the case LC and 0.59 for the case HC. The higher value in case $\mathrm{HC}$ is caused by the high relative humidity and the high aerosol concentrations, especially on 20 August. The average reduction of the global radiation (run F-run $\mathrm{R}$ ) is $-5.3 \mathrm{~W} \mathrm{~m}^{-2}$ in case $\mathrm{LC}$ and $-6.0 \mathrm{~W} \mathrm{~m}^{-2}$ in case $\mathrm{HC}$. Although the aerosol optical depth is almost three times greater than in case LC the average global radiation change does not differ too much between cases HC and LC as the global radiation in case HC is much lower than in case LC. The average $2 \mathrm{~m}$ temperature differences between runs $\mathrm{F}$ and $\mathrm{R}$ are $-0.10 \mathrm{~K}(\mathrm{LC})$ and $-0.08 \mathrm{~K}(\mathrm{HC})$. This means that over Germany the simulated aerosols induce a temperature reduction.

We have calculated the mean daily temperature range for Germany for each day of the two episodes. The mean daily temperature ranges and the differences (run $\mathrm{F}-$ run $\mathrm{R}$ ) are given in Table 6 . The strong decrease of the daily temperature range at the third day of episode $\mathrm{HC}$ is due to a frontal system that passes over Germany (see supplemental material: http://www.atmos-chem-phys.net/9/ 8661/2009/acp-9-8661-2009-supplement.pdf). The radiative feedback caused by the aerosol particles produces a reduction in the daily temperature range of about $0.13 \mathrm{~K}$. This decrease is in the same order as the observed weekly cycle of the temperature range (Bäumer and Vogel, 2007).

The results of our model runs cannot be used to prove or to explain the observed weekly cycles since we have carried out our model simulations with emissions that were constant from day to day. While Bäumer and Vogel (2007) related the weekly cycles in the atmospheric variables to the weekly cycle of anthropogenic emissions, this study takes anthropogenic and biogenic emissions into account. Moreover, we have simulated only two episodes and the interaction with microphysics has been neglected. However, the results serve as a rough estimation of the effects of aerosol particles that can be expected on the regional scale. As COSMO-ART is currently being improved to treat the interaction of aerosols with clouds, a real simulation of the effects of changing emissions during a week will be carried out in future applications of the model system.

\section{Summary and conclusions}

We have built up the new model system COSMO-ART for studying the interaction of aerosol particles with the atmosphere on the regional scale. The model system is based on the operational weather forecast model COSMO of the Deutscher Wetterdienst. It is fully online coupled with detailed photochemistry and aerosol dynamics of natural and anthropogenic aerosol particles. The photochemistry includes the reactions that lead to the formation of precursors of aerosol particles. Within the model primary particles such as mineral dust, sea salt and soot are treated together with secondary particles consisting of sulphate, ammonia, nitrate, organic compounds and water. The size distribution of the particles and their chemical composition vary in space and time depending on transport processes, emissions, 
Table 6. Mean daily values of TR and $\Delta \mathrm{TR}$ for the sub domain that covers Germany for cases LC and HC.

\begin{tabular}{lcrrr}
\hline Episode & day & TR in K (run R) & TR in K (run F) & $\Delta$ TR in K \\
\hline \multirow{3}{*}{ LC } & 30 Aug 2005 & 7.63 & 7.53 & -0.10 \\
& 31 Aug 2005 & 10.13 & 9.98 & -0.15 \\
& 01 Sep 2005 & 11.42 & 11.25 & -0.17 \\
$\mathrm{HC}$ & 18 Aug 2005 & 11.31 & 11.22 & -0.09 \\
& 19 Aug 2005 & 9.02 & 8.91 & -0.11 \\
& 20 Aug 2005 & 2.57 & 2.39 & -0.18 \\
\hline
\end{tabular}

and the chemical processes. Based on very detailed calculations we have developed parameterisations to treat the impact of the aerosol particles on the atmospheric short and long wave radiation. Applying these parameterisations within COSMO-ART we are able to quantify the feedback processes, between the aerosols and the state of the atmosphere, that are initialized by changes in radiation on the regional scale in a fully coupled way. We have applied the model system to two episodes in August 2005 that differed in cloud cover over Western Europe. The simulated $\mathrm{PM}_{10}$ concentrations have been compared to the observed ones and an underestimation of the observations in the order of $40 \%$ was found. This is comparable with the results of other model studies. Reasons for the underestimation are missing emissions and probably an underestimation of the organic fraction of the particles.

For each episode two series of model runs were carried out, one where the interaction of the aerosol particles with radiation was switched off and one where it was taken into account. This approach allows the estimation of the direct radiative aerosol effect on the atmosphere at short timescales on the regional scale. For the case with a low amount of clouds we found a good correlation between the aerosol optical depth and the changes in $2 \mathrm{~m}$ temperature. Locally, the reduction of the averages over three days of the temperature reached values of $0.3 \mathrm{~K}$. For cloud free conditions the atmosphere responses quite rapidly to the aerosol optical depth. In the case of cloudy conditions this correlation is weaker. When clouds are present the aerosols cause changes in the cloud cover or in the cloud water content which amplify the pure radiative effect due to the aerosols. In most parts of the model domain this leads to a cooling effect, but under certain conditions also an increase of the averaged temperature is simulated.

We calculated the changes in the daily temperature range over Germany. For both episodes the aerosol leads to a reduction of the daily temperature range in the order of magnitude of $0.1 \mathrm{~K}$. This value is in the same order of magnitude as was found from observation of weekly cycles of this parameter. As we underestimated the observed aerosol concentration our findings represent a lower limit of the aerosol effect.
Acknowledgements. We thank U. Schättler from DWD for his great support and patience during the construction phase of COSMO-ART. Acknowledgement is made for the use of ECMWF's computing and archive facilities through, the special project "Mesoscale modelling using the DWD COSMO-Model". We also acknowledge the MODIS mission scientists and associated NASA personnel for the production of the data used in this research effort.

Edited by: W. Birmili

\section{References}

Acker, J. G. and Leptoukh, G.: Online Analysis Enhances Use of NASA Earth Science Data, Eos, Trans. AGU, 88, 14-17, 2007.

Ackermann, I., Hass, H., Memmesheimer, M., Ebel, A., Binkowski, F., and Shankar U.: Modal aerosol dynamics model for Europe: Development and first applications, Atmos. Environ., 32, 29812999, 1998.

Bäumer, D. and Vogel, B.: An unexpected pattern of distinct weekly periodicities in climatological variables in Germany, Geophys. Res. Lett., 34, L03819, doi:10.1029/2006GL028559, 2007.

Bäumer, D., Lohmann, U., Lesins, G., Li, J., and Croft, B.: Parameterizing the optical properties of carbonaceous aerosols in the Canadian Centre for Climate Modeling and Analysis Atmospheric General Circulation Model with impacts on global radiation and energy fluxes, J. Geophys. Res., 112, D10207, doi:10.1029/2006JD007319, 2007.

Bäumer, D. and Vogel, B.: Reply to comment by H. J. Hendricks Franssen on "An unexpected pattern of distinct weekly periodicities in climatological variables in Germany", Geophys. Res. Lett., 35, L05803, doi:10.1029/2007GL032432, 2008.

Bäumer, D., Rinke, R., and Vogel, B.: Weekly periodicities of Aerosol Optical Thickness over Central Europe - evidence of an anthropogenic direct aerosol effect, Atmos. Chem. Phys., 8, 8390, 2008, http://www.atmos-chem-phys.net/8/83/2008/.

Bell, T. L., Rosenfeld, D., Kim, K.-M., Yoo, J.-M., Lee, M.-I., and Hahnenberger, M.: Midweek increase in US summer rain and storm heights suggests air pollution invigorates rainstorms, J. Geophys. Res., 113, D02209, doi:10.1029/2007JD008623, 2008.

Binkowski, F. S. and Shankar, U.: The regional particulate matter model, 1. Model description and preliminary results, J. Geophys. 
Res., 100, 26191-26209, 1995.

Bohn, B. and Zetzsch, C.: Rate constants of $\mathrm{HO}_{2}+\mathrm{NO}$ covering atmospheric conditions: $1 . \mathrm{HO}_{2}$ formed by $\mathrm{OH}+\mathrm{H}_{2} \mathrm{O}_{2}$, J. Phys. Chem., 101, 1488-1493, 1997.

Bohren, C. F. and Huffman, D. R.: Absorption and Scattering of Light by Small Particles, Wiley, New York, 1983.

Crawford, J., Shetter, R., Lefer, B., Cantrell, C., Junkermann, W., Madronich, S., and Calvert, J.: Cloud impacts on UV spectral actinic flux observed during IPMMI, J. Geophys. Res., 108, 8548, doi:10.1029/2002JD002731, 2003.

Cui, Z., Carslaw, K. S., Yin, Y., and Davies, S.: A numerical study of aerosol effects on the dynamics and microphysics of a deep convective cloud in a continental environment, J. Geophys. Res., 111, D05201, doi:10.1029/2005JD005981, 2006.

de Forster, P. M. and Solomon, S.: Observations of a "weekend effect" in diurnal temperature range, P. Natl. Acad. Sci. USA, 100, 11225-11230, 2003.

Donahue, N. M., Dubey, M. K., Mohrschladt, R., Demerjian, K. L., and Anderson, J. G.: High pressure flow study of the reactions $\mathrm{OH}+\mathrm{NO} \mathrm{HONO}$, Errors in the falloff region, J. Geophys. Res., 102, 6153-6163, 1997.

EEA: available at:http://dataservice.eea.europa.eu/dataservice/ metadetails.asp?id=1029, last access: 5 November 2008, 2008.

Franssen, H. J.: Comment on "An unexpected pattern of distinct weekly periodicities in climatological variables in Germany" by Bäumer, D. and Vogel, B., Geophys. Res. Lett., 35, L05802, doi:10.1029/2007GL031279, 2008.

Geiger, H., Barnes, I., Bejan, I., Benter, T., and Spittler, M.: The tropospheric degradation of isoprene: an updated module for the regional atmospheric chemistry mechanism, Atmos. Environ., 37, 1503-1519, 2003.

Gong, D.-Y., Guo, D., and Ho, C.-H.: Weekend effect in diurnal temperature range in China: Opposite signals between winter and summer, J. Geophys. Res., 111, D18113, doi:10.1029/2006JD007068, 2006.

Grell, G. A., Peckham, S. E., Schmitz, R., McKeen, S. A., Frost, G., Skamarock, W. C., and Eder, B.: Fully coupled "online" chemistry within the WRF model, Atmos. Environ., 39, 6957-6975, 2005.

Hoose, C., Lohmann, U., Bennartz, R., Croft, B., and Lesins, G.: Global simulations of aerosol processing in clouds, Atmos. Chem. Phys., 8, 6939-6963, 2008, http://www.atmos-chem-phys.net/8/6939/2008/.

IPCC: Climate Change 2007 - The physical science basis. Contribution of working group I to the Fourth Assessment Report of the Intergovernmental Panel on Climate Change, Cambridge University Press, Cambridge, 2007.

Jacobson, M. Z.: A physically based treatment of elemental carbon optics: Implications for global direct forcing of aerosols, Geophys. Res. Lett., 27, 217-220, 2000.

Kerminen, V.-M. and Wexler, A. S.: Post-fog nucleation of $\mathrm{H}_{2} \mathrm{SO}_{4}$ $-\mathrm{H}_{2} \mathrm{O}$ particles in smog, Atmos. Environ., 28, 2399-2406, 1994.

Khain, A., Pokrovsky, A., Pinsky, M., Seifert, A., and Phillips, V. T. J.: Simulation of effects of atmospheric aerosols on deep turbulent convective clouds by using a spectral microphysics mixedphase cumulus cloud model, Part 1: Model description and possible applications, J. Atmos. Sci., 61, 2963-2982, 2004.

Kim, Y. P., Seinfeld, J. H., and Saxena, P.: Atmospheric gas-aerosol equilibrium I. Thermodynamic model, Aerosol Sci. Tech., 19,
157-181, 1993.

Landgraf, J. and Crutzen, P. J.: An efficient method for online calculations of photolysis and heating rates, J. Atmos. Sci., 55, 863-878, 1998.

Levin, Z., Teller, A., Ganor, E., and Yin, Y.: On the interactions of mineral dust, sea-salt particles, and clouds: A measurement and modeling study from the Mediterranean Israeli Dust Experiment campaign, J. Geophys. Res., 110, D20202, doi:10.1029/2005JD005810, 2005.

Lohmann, U.: Global anthropogenic aerosol effects on convective clouds in ECHAM5-HAM, Atmos. Chem. Phys., 8, 2115-2131, 2008 , http://www.atmos-chem-phys.net/8/2115/2008/.

Lohmann, U. and Schwartz, S. E.: Aerosols and Clouds in Chemical Transport Models and Climate Models, in: Clouds in the Perturbed Climate System: Their Relationship to Energy Balance, Atmospheric Dynamics, and Precipitation, edited by: Heintzenberg, J. and Charlson, R. J., MIT Press, 531-556, 2009.

Ludwig, J., Meixner, F. X., Vogel, B., and Förstner, J.: Processes, influencing factors, and modelling of nitric oxide surface exchange - An overview, Biogeochemistry, 52(2), 225-257, 2001.

Lundgren, K.: Numerical Simulation of the Spatial and Temporal Distribution of Sea Salt Particles on the Regional Scale, M. Sc. thesis, Department of Meteorology Stockholm University, Stockholm, Sweden, 2006.

Mårtensson, E. M., Nilsson, D., De Leeuw, G., Cohen, L. H., and Hansson, H.-C.: Laboratory simulations and parameterization of the primary marine aerosol production, J. Geophys. Res., 108, 4297-4308, 2003.

Mircea, M. and Stefan, S.: A theoretical study of the microphysical parameterization of the scavenging coefficient as a function of precipitation type and rate, Atmos. Environ., 32, 2931-2938, 1998.

Monhanan, E. C., Spiel, D. E., and Davidson, K. L.: A model of marine aerosol generation via whitecaps and wave disruption in oceanic whitecaps, Monahan, E. C. and Mac Niocaill, G., D. Reidel, 167-174, 1986.

Noppel, H., Blahak, U., and Beheng, K. D.: Cloud resolving simulations of a severe hailstorm: influence of $\mathrm{CCN}$ conditions, Geophys. Res. Abstr., 9, 08883, 2007.

O’Dowd, C. D., Smith, M. H., Consterdine, I. E., and Lowe, J. A.: Marine aerosol, sea-salt, and the marine sulphur cycle: A short review, Atmos. Environ., 31, 73-80, 1997.

Odum, J. R., Hoffmann, T., Bowman, F., Collins, D., Flagan, R. C., and Seinfeld, J. H.: Gas/Particle partitioning and secondary organic aerosol yields, Environ. Sci. Technol., 30, 2580-2585, 1996.

Pregger, T., Thiruchittampalam, B., and Friedrich, R.: Ermittlung von Emissionsdaten zur Untersuchung der Klimawirksamkeit von Rußpartikeln in Baden-Württemberg, Final Report, IER Universität Stuttgart, 2007.

Riemer, N.: Numerische Simulationen zur Wirkung des Aerosols auf die Troposphärische Chemie und die Sichtweite, $\mathrm{Ph}$. D. thesis, Inst. für Meteorol. und Klimaforsch. der Univ. Karlsruhe (TH), Karlsruhe, Germany, 2002.

Riemer, N., Vogel, H., Vogel, B., and Fiedler, F.: Modeling aerosols on the mesoscale- $\gamma$ : Treatment of soot aerosol and its radiative effects, J. Geophys. Res., 109, 4601, doi:10.1029/2003JD003448, 2003a. 
Riemer, N., Vogel, H., Vogel, B., Schell, B., Ackermann, I., Kessler, C., and Hass, H.: The impact of the heterogeneous hydrolysis of $\mathrm{N}_{2} \mathrm{O}_{5}$ on tropospheric chemistry and nitrate aerosol formation, $\mathrm{J}$. Geophys. Res., 108, 4144, doi:10.1029/2002JD002436, 2003b.

Riemer, N., Vogel, H., and Vogel, B.: Soot aging time scales in polluted regions during day and night, Atmos. Chem. Phys., 4, 1885-1893, 2004, http://www.atmos-chem-phys.net/4/1885/2004/.

Rinke, R.: Parametrisierung des Auswaschens von Aerosolpartikeln durch Niederschlag, $\mathrm{Ph}$. D. thesis, Inst. für Meteorol. und Klimaforsch. der Univ. Karlsruhe (TH), Karlsruhe, Germany, 2008.

Ritter, B. and Geleyn, J.-F.: A comprehensive scheme for numerical weather prediction models with potential applications in climate simulations, Mon. Weather Rev., 120, 303-325, 1992.

Ruggaber, A., Dlugi, R., and Nakajiima, T.: Modelling radiation quantities and photolysis frequencies in the troposphere, J. Atmos. Chem., 18, 171-210, 1994.

Sartelet, K., Debry, E., Fahey, K., Roustan, Y., Tombette, M., and Sportisse, B.: Simulation of aerosols and gas-phase species over Europe with the Polyphemus system, Part I: model-todata comparison for 2001, Atmos. Environ., 41, 6116-6131, doi:10.1016/j.atmosenv.2007.04.024, 2007.

Sarwar, G., Roselle, S. J., Mathur, R., Appel, W., Dennis, R. L., and Vogel, B.: A comparison of CMAQ HONO predictions with observations from the Northeast Oxidant and Particle Study, Atmos. Environ., 42, 5762-5772, 2008.

Schell, B., Ackermann, I. J., Binkowski, F. S., and Ebel, A.: Modeling the formation of secondary organic aerosol within a comprehensive air quality model system, J. Geophys. Res., 106, 2827528293, 2001.

Smith, M. H., Park, P. M., and Consterdine, I. E.: Marine aerosol concentrations and estimated fluxes over the sea, Q. J. Roy. Meteorol. Soc., 119, 809-824, 1993.

Stanelle, T.: Wechselwirkungen von Mineralstaubpartikeln mit thermodynamischen und dynamischen Prozessen in der Atmosphäre über Westafrika, Ph. D. thesis, Inst. für Meteorol. und Klimaforsch. der Univ. Karlsruhe (TH), Karlsruhe, Germany, 2008.

Steppeler, J., Doms, G., Schättler, U., Bitzer, H., Gassmann, A., Damrath, U., and Gregoric, G.: Meso gamma scale forecasts using the nonhydrostatic model LM, Meteorol. Atmos. Phys., 82, 75-96, 2002.

Stern, R., Builtjes, P., Schaap, M., Timmermans, R., Vautard, R., Hodzic, A., Memmesheimer, M., Feldmann, H., Renner, E., Wolke, R., and Kerschbaumer, A.: A model inter-comparison study focussing on episodes with elevated $\mathrm{PM}_{10}$ concentrations, Atmos. Environ., 42, 4567-4588, 2008.
Stier, P., Feichter, J., Kinne, S., Kloster, S., Vignati, E., Wilson, J., Ganzeveld, L., Tegen, I., Werner, M., Balkanski, Y., Schulz, M., Boucher, O., Minikin, A., and Petzold, A.: The aerosolclimate model ECHAM5-HAM, Atmos. Chem. Phys., 5, 11251156, 2005, http://www.atmos-chem-phys.net/5/1125/2005/.

Stockwell, W. R., Middleton, P., and Chang, J. S.: The second generation regional acid deposition model chemical mechanism for regional air quality modelling, J. Geophys. Res., 95, 1634316367, 1990

Tiedtke, M.: A comprehensive mass flux scheme for cumulus parameterization in large-scale models, Mon. Weather Rev., 117, 1779-1800, 1989.

Vogel, B., Fiedler, F., and Vogel, H.: Influence of topography and biogenic volatile organic compounds emission in the state of Baden-Württemberg on ozone concentrations during episodes of high air temperatures, J. Geophys. Res., 100, 22907-22928, 1995.

Vogel, B., Vogel, H., Kleffmann, J., and Kurtenbach, R.: Measured and simulated vertical profiles of nitrous acid, Part II - Model simulations and indications for a photolytic source, Atmos. Environ. 37, 2957-2966, 2003.

Vogel, B., Hoose, C., Vogel, H., and Kottmeier, C.: A model of dust transport applied to the Dead Sea area, Meteorol. Z., 14, 611-624, 2006.

Vogel, H., Pauling, A., and Vogel, B.: Numerical simulation of birch pollen dispersion with an operational weather forecast system, Int. J. Biometeorol., 52, 805-814, doi:10.1007/s00484-0080174-3, 2008.

Weingartner, E., Burtscher, H., and Baltensperger, U.: Hygroscopic properties of carbon and diesel soot particles, Atmos. Environ., 31, 2311-2327, 1997.

Whitby, E. R., McMurray, P. H., Shankar, U., and Binkowski, F. S.: Modal Aerosol Dynamics Modeling, Technical Report 600/391/020, (NTIS PB91-161729/AS Natl. Tech. Inf. Serv. Springfield, Va.), Atmos. Res. and Exposure Assess. Lab. U.S. Environ. Prot. Agency, Research Triangle Park, N.C., 1991.

Wild, O., Zhu, X., and Prather, M. J.: Fast-J: Accurate Simulation of In and Below-Cloud Photolysis in Tropospheric Chemical Models, J. Atmos. Chem., 37, 245-282, doi:10.1023/A:1006415919030, 2000.

Wippermann, F.: The applicability of several approximations in meso-scale modelling - A linear approach, Contrib. Atmos. Phys., 54, 298-308, 1980.

Yienger, J. J. and Levy, H.: Empirical model of global soil-biogenic NO $_{x}$ emissions, J. Geophys. Res., 100, 11447-11464, 1995.

Zhang, Y.: Online-coupled meteorology and chemistry models: history, current status, and outlook, Atmos. Chem. Phys., 8, 2895 2932, 2008,

http://www.atmos-chem-phys.net/8/2895/2008/. 